\title{
LA TEORÍA \\ DE LA EFICIENCIA DINÁMICA
}

\author{
JESÚS HUERTA DE SOTO*
}

Resumen. En este trabajo se presenta un concepto alternativo de eficiencia económica de carácter dinámico y que pretende superar al concepto estático de origen paretiano hasta ahora dominante. Tras explicar el proceso de formación del concepto paretiano, se propone reintroducir la dimensión dinámica de la eficiencia basada en la capacidad creativa y coordinadora de la función empresarial. Se estudian, asimismo, las íntimas relaciones que existen entre la ética, la moral personal y la dimensión dinámica de la eficiencia económica, proponiendo la aplicación del nuevo criterio de eficiencia a distintos campos de la ciencia económica.

Abstract. This paper presents an alternative, dynamic view of economic efficiency as a replacement for the static Paretian approach prevalent until now. The development of the Paretian perspective is traced, and a proposal is then made to reintroduce the dynamic aspect of efficiency, a dimension based on the creative, coordinating potential of entrepreneurship. In addition, the close relationship between ethics, personal morals, and the dynamic aspect of economic efficiency is studied, and the application of the new criterion of efficiency to various areas of economics is suggested.

Palabras clave: eficiencia estática, óptimo de pareto, eficiencia dinámica, creatividad empresarial, coordinación, función empresarial, proceso de mercado, ética.

Códigos JEL: A12, B53, D61, D63, H2, K1 1, P14, Z12

* Catedrático de Economía Política, Universidad Rey Juan Carlos, Madrid. Web: www.jesushuertadesoto.com. Correo: huertadesoto@dimasoft.es 


\section{Introducción}

Los criterios tradicionales de eficiencia asignativa de origen paretiano, que con carácter predominante se han utilizado hasta ahora en la ciencia económica, adolecen de un marcado carácter estático y, por tanto, son insuficientes para ser aplicados como criterios normativos a la rica dinámica de las instituciones sociales que se dan en la vida real ${ }^{1}$. Por esta razón, es preciso sustituir el criterio tradicional de eficiencia por un criterio alternativo, que vamos a denominar "criterio de eficiencia dinámica» que, por un lado, sea capaz de colmar las grandes lagunas de los criterios tradicionales de origen paretiano y, por otro lado, permita su fácil aplicación al ámbito de las instituciones sociales.

El presente trabajo consta de tres apartados claramente diferenciados. En el primero se efectuará un repaso del proceso de formación del concepto de eficiencia paretiana. Este criterio se desarrolla a imagen y semejanza de la idea de eficiencia energética que surge en el ámbito de la física y la mecánica en el siglo XIX. Esto explica por qué el criterio tradicional de eficiencia paretiana, que se ha convertido en el eje sobre el que pivota toda la economía del bienestar y gran parte del análisis económico del derecho, se encuentra profundamente encorsetado en la estática comparativa y, por tanto, es difícilmente aplicable a la rica dinámica institucional.

En la segunda parte se presenta el concepto alternativo de eficiencia dinámica, que surge como resultado natural de la teoría de los procesos de mercado impulsados por la capacidad, a la vez creativa y coordinadora, de la función empresarial. Aunque hasta ahora el criterio de eficiencia dinámica no ha logrado introducirse con carácter general en nuestra disciplina, son diversos los autores que han cultivado el campo de la eficiencia dinámica. Economistas de la talla de Mises, Hayek y Schumpeter, u otros

\footnotetext{
1 Véase Huerta de Soto (2001) (a) y (2002) (a).
} 
más próximos a nosotros como Rothbard, Kirzner, North, con su concepto de «eficiencia adaptativa», o el propio Leibestein, con su concepto de «eficiencia-X», se han preocupado de una $u$ otra forma por desarrollar o proponer criterios alternativos, en mayor o menor medida coincidentes o próximos a nuestro concepto de la eficiencia dinámica. En esta parte estudiaremos, relacionándolas entre sí, las diversas aportaciones en este campo de dichos autores.

El último y tercer apartado de este artículo se centrará en analizar uno de los aspectos que consideramos más relevantes y prometedores del mismo, a saber, el estudio de la íntima relación que en nuestra opinión existe entre el criterio propuesto de eficiencia dinámica y el marco de principios éticos que prepondere en cada sociedad. Por un lado, se abre un importante y fructífero campo de investigación para los futuros economistas que consistiría en la aplicación sistemática del criterio de eficiencia dinámica a cada una de las instituciones sociales (jurídicas, morales y económicas) para hacer posible una evaluación específica de las mismas según un criterio distinto del tradicional paretiano. Por otro, el análisis efectuado nos va a permitir identificar qué principios éticos son los que hacen posible la eficiencia dinámica $\mathrm{y}$, por tanto, el desarrollo y el avance coordinado de la sociedad y la civilización. De esta manera habríamos logrado establecer una relación directa entre el ámbito de la ciencia económica y el ámbito de la ética, impulsándose una muy fructífera relación entre ambas disciplinas, que se verán así mutuamente reforzadas. 


\section{La formación del criterio de eficiencia estática: un análisis crítico}

\section{a) Antecedentes históricos}

El término «eficiencia» procede etimológicamente del latín efficiens que, a su vez, viene del verbo latino ex facio, que significa «sacar algo de». ${ }^{2}$ Esta idea de la eficiencia como la capacidad de «sacar algo de», aplicada al ámbito económico, es anterior al mundo romano y puede remontarse incluso hasta la Grecia clásica, donde se utiliza por primera vez el término «economía» (oikonomìa) para referirse a la administración eficiente de la hacienda o casa familiar. Así, en el Económico, Jenofonte, 380 años antes de Jesucristo, pone en boca de Sócrates que la economía es «un saber» que «permite a los hombres acrecentar su hacienda»; considerando que la hacienda es «lo mismo que la totalidad de las propiedades», y definiendo la propiedad como «lo provechoso para la vida de cada cual». ${ }^{3}$ Ahora bien, el propio Jenofonte, tras esta definición tan moderna y subjetivista de la economía, se preocupa, en los diálogos subsiguientes, de explicar cómo existen dos formas distintas de acrecentar la hacienda, equiparables en última instancia a dos dimensiones diferentes del concepto de eficiencia.

Por un lado, la dimensión que podríamos calificar de «eficiencia estática» y que sería aquella que consiste en la buena gestión de los recursos disponibles (o «dados») tendente a evitar su despilfarro. Según Jenofonte, esta gestión eficiente se conseguiría, ante todo, manteniendo en buen orden las cosas de la casa, ${ }^{4}$ así como supervisando con todo cuidado la administración de sus bienes, vigilándolos y cuidándolos de la mejor manera posible. Jenofonte concluye, como resumen del conjunto de habilidades que son precisas para la gestión eficiente de los recur-

2 Blánquez (1998), p. 567, 2. a acepción.

3 Jenofonte (1966), p. 316.

4 «Nada hay tan útil, mujer, ni tan bello para los hombres como el orden.» Jenofonte (1966), p. 338. 
sos «dados», con la atinada respuesta atribuida al gran rey bárbaro que «tropezó con un buen caballo, y queriendo engordarle en el más corto plazo, preguntó a uno de los que pasaban por entendidos en caballos qué engorda lo antes posible al caballo. Y se dice que éste respondió: «el ojo de su amo». De igual modo, Sócrates, me parece que en cualquier cosa es el ojo del amo lo que obtiene los mejores resultados. $\gg^{5}$

Pero junto a esta dimensión del concepto de eficiencia que hemos calificado de "estática», Jenofonte da entrada también a una dimensión complementaria de carácter «dinámico», que consiste en tratar de incrementar la hacienda actuando empresarialmente y comerciando con ella. Se trata, en suma, de aumentar los bienes por vía de la creatividad empresarial, es decir, del comercio y la especulación, más que evitando el despilfarro de los recursos que ya se poseen. Dos son los ejemplos de actividades concretas que Jenofonte presenta para ilustrar este quehacer basado en la creatividad empresarial. Por un lado, el comprar tierras mal cultivadas o yermas, mejorándolas y vendiéndolas después mucho más caras. ${ }^{6}$ Otro ejemplo de eficiencia dinámica que permite incrementar la hacienda y allegar nuevos recursos que antes no se poseían es el de aquellos comerciantes que compran trigo allí donde éste es abundante y, por tanto, barato, y lo transportan y venden mucho más caro allí donde, por existir sequía o una mala cosecha, se ha propagado la escasez y el hambre. ${ }^{7}$

5 Ib., p. 380.

${ }^{6}$ «El método más eficaz para hacer dinero con la agricultura, siempre que se sea capaz de tener diligencia y se trabaje la tierra con ahínco, lo puso en práctica mi padre y me lo enseñó. En modo alguno permitía comprar un terreno bien cultivado; aconsejaba comprar, por el contrario, aquel que, por la desidia o la incapacidad de sus propietarios, estuviera yermo o desplantado. Decía, en efecto, que los terrenos bien cultivados cuestan mucho dinero y no pueden mejorarse... Y nada queda más mejorado que un campo convertido, de yermo, en productivo. Ten por cierto, Sócrates, que conseguimos que muchos terrenos alcanzaran una cotización mucho más alta que su valor originario.» Jenofonte (1966), p. 426.

7 «Los comerciantes, en efecto, poseídos de una fervorosa pasión por el trigo, doquiera más abunde, allí navegan en su busca, surcando el mar Egeo, el ponto 
Esta tradición de distinguir claramente entre dos dimensiones distintas del concepto de eficiencia, la estática y la dinámica, continúa incluso hasta la Edad Media. Así, por ejemplo, para San Bernardino de Siena están justificadas las rentas de comerciantes y artesanos en base a su industria y pericula, es decir, por un lado, por la buena y diligente gestión de sus recursos (dados), es decir, el comportamiento diligente típicamente orientado a evitar el despilfarro (eficiencia estática), y por otro lado en base a la asunción de los riesgos y peligros (pericula) que se derivan de toda especulación empresarial (eficiencia dinámica). ${ }^{8}$

\section{b) La influencia de la física mecánica}

Sin embargo, y a pesar de estos esperanzadores antecedentes, a partir del advenimiento de la Edad Moderna el concepto de eficiencia económica paulatinamente se estrecha y reduce, hasta llegar a referirse con carácter exclusivo a la dimensión estática, es decir, al actuar diligente dirigido a evitar el despilfarro de los recursos «dados». En esta evolución reduccionista, que empobrece notablemente el concepto de eficiencia con sus dos dimensiones distintas que ya había articulado Jenofonte, tiene una influencia determinante la forma en que el surgimiento y desarrollo de la física mecánica termina afectando a la evolución del pensamiento económico, especialmente a partir del siglo XIX.

En efecto, con el advenimiento de la modernidad, la física sustituye a la astronomía como «ciencia por antonomasia», y termina construyéndose sobre el concepto de «energía», concepto abstracto del que todos los físicos hablan y discuten, aunque

Euxino y el mar de Sicilia. Acto seguido, cogen la mayor cantidad posible y lo transportan a través del mar, cargándole incluso en el mismo barco en que ellos navegan. Y cuando se ven en precisión de dinero, no se deshacen de él en cualquier lugar y a la buena ventura, sino que, doquiera que tenga el trigo un valor más alto y de mayor estima goce, allí lo llevan para entregarlo a sus habitantes.» Jenofonte, (1966) p. 428.

8 Rothbard (1999), p. 114. 
no se pongan muy de acuerdo sobre lo que exactamente sea la energía, salvo cuando observan sus efectos en forma de fuerza o movimiento. ${ }^{9}$ En este sentido, la «ley de la conservación de la energía» llega a adquirir un papel protagonista en el desenvolvimiento de la física, y a nuestros efectos no debe pasar por alto su carácter esencialmente estático ( «la energía ni se crea ni se destruye, tan sólo se transforma...»). Posteriormente, la segunda ley de la termodinámica enuncia que en todo proceso físico hay una parte de energía que se despilfarra, por ejemplo en forma de calor que se disipa, por lo que los sistemas físicos no serían reversibles. Ambas leyes protagonizan el gran desenvolvimiento de la física a lo largo del siglo XIX y explican por qué la mayoría de los científicos conciben los fenómenos físicos casi exclusivamente en términos de «energía». Además, la principal aplicación práctica de la ciencia física se plasma en el desarrollo de la ingeniería mecánica, construida exclusivamente sobre el concepto (estático) de eficiencia energética, que se define por los ingenieros como la «minimización en el despilfarro de energía». Un ejemplo muy ilustrativo es el de la máquina de vapor, que se convierte en el bien de capital más típico en la Revolución Industrial. La máquina de vapor sirve para transformar calor en movimiento y levantamiento de pesos, siendo el objetivo de todo buen ingeniero mecánico el lograr el máximo de eficiencia (estática), entendida como el máximo de movimiento con el mínimo de consumo o despilfarro de energía.

Esta concepción reduccionista de la eficiencia (estática) termina señoreándose también del lenguaje coloquial. Así, en inglés, el Webster's Dictionary califica de «eficiente» a toda acción «que minimiza el despilfarro». ${ }^{10}$ En español, la idea de eficiencia

${ }^{9}$ De hecho, el término «energía» etimológicamente también procede del griego y significa «acción vigorosa».

${ }_{10}$ «Marked by ability to choose and use the most effective and least wasteful means of doing a task or accomplishing a purpose», Webster's Third New International Dictionary, Encyclopedia Britannica, Chicago y Londres 1981, Vol. I, p. 725 (las cursivas son mías). 
está íntimamente relacionada con la capacidad de conseguir un efecto o rendimiento determinado, y el Diccionario de la Lengua Española define el término rendimiento como la «proporción entre el producto o resultado obtenido y los medios utilizados» ${ }^{11}$ (se supone que, uno y otros dados o conocidos).

Ahora bien, quizás en este momento lo más importante sea resaltar la negativa influencia que la concepción estática de la eficiencia energética ha tenido sobre el desarrollo de la ciencia económica. Así, Hans Mayer ${ }^{12}$ y Philip Mirowski han señalado cómo la economía neoclásica se desarrolla como una copia de la física mecánica del siglo XIX, con unidad de técnica formal, sustituyendo el concepto de energía por el de utilidad y aplicando los mismos principios de conservación, maximización del resultado y minimización del despilfarro. ${ }^{13}$

El autor más conocido y característico que ilustra mejor esta influencia de la física sobre la ciencia económica es Leon Walras. En su artículo «Económica y mecánica», publicado en 1909, argumenta que la ciencia físico-matemática y sus Elementos de economía teórica pura utilizan idénticas fórmulas matemáticas, insistiendo en el paralelismo existente entre los conceptos de fuerza y rareté (considerados como vectores por Walras), por un lado, y los de energía y utilidad (considerados por Walras como cantidades escalares), por otro lado. ${ }^{14}$

En suma, la influencia de la física mecánica hace que desaparezca la dimensión creadora y especulativa que, desde sus orígenes, tenía el concepto de eficiencia económica, quedando tan sólo

11 Diccionario de la Lengua Española, Real Academia Española, Espasa Calpe, Madrid 1992, pp. 1254 y 559.

12 Mayer (1994).

${ }_{13}$ Mirowski (1989). Posteriormente, Mirowski (2002) ha refinado aún más su análisis crítico sobre el mecanicismo de la escuela neoclásica, que él califica de «Cyborg incursion into economics».

${ }_{14}$ "Aussi a-ton déjà signalé celles des forces et des raretés comme vecteurs, d'une part, et celles des énergies et des utilités comme quantités scalaires, d'autre part.» Walras, «Economique et Mécanique», Bulletin de la Société Vaudoise de Sciences Naturelles, n. ${ }^{\circ} 45$, p. 318 (citado por Mirowski, ob. cit., p. 220). 
la dimensión reduccionista y estática de dicho concepto, centrada exclusivamente en el objetivo de minimizar el despilfarro de unos recursos económicos que se consideran conocidos y dados. Así, y por vía de ejemplo, puede recordarse la definición que de la voz «eficiencia asignativa» da The New Palgrave Dictionary of Economics, debida a Stanley Reiter, y que dice que es la «maximización de la satisfacción de necesidades sometida a restricciones de recursos y tecnología» dados. ${ }^{15}$

Que el artículo dedicado a la eficiencia económica del que sin duda alguna es el diccionario más importante de nuestra disciplina no mencione en forma alguna la dimensión dinámica del concepto de eficiencia económica es tan ilustrativo como desalentador. Especialmente teniendo en cuenta que en la vida real ni los recursos ni la tecnología están «dados», sino que pueden variar y de hecho varían continuamente como resultado de la creatividad empresarial. Y si varían, es obvio que existe toda una dimensión del concepto de eficiencia (la dimensión dinámica) que es de rancio abolengo (pues, como ya hemos visto, puede remontarse incluso hasta Jenofonte) y sólo puede olvidarse con un alto coste para el análisis económico de la realidad.

El concepto reduccionista de eficiencia estática tiene también un gran impacto en el mundo de la organización empresarial desde principios del siglo XX con el surgimiento del taylorismo. En efecto, Frederick W. Taylor, en su conocido libro The Principles of Scientific Management (1911), propugna que en todas las industrias se establezca un departamento de «eficiencia productiva» cuyos objetivos serían: primero, controlar a los trabajadores; segundo, medir sus tiempos de trabajo; y tercero, evitar todo tipo de despilfarro. ${ }^{16}$ De hecho, este concepto reduccionista de la eficiencia estática se convierte en una especie de ídolo al

15 The New Palgrave Dictionary of Economics, John Eatwell, Murray Milgate y Peter Newman (eds.), Macmillan, Londres 1987, vol. II, p. 107.

16 Taylor (1967) p. 69. 
que parece que hay que sacrificarlo todo, extendiéndose esta obsesión (que quizás podría calificarse mejor como «culto») por la eficiencia estática incluso al ámbito de la ideología política.

Un ejemplo interesante de este fenómeno es el representado por el matrimonio de socialistas fabianos compuesto por Sydney y Beatriz Webb que, escandalizados ante los «despilfarros» que observan en el sistema capitalista, se deciden a fundar la London School of Economics con el objetivo de impulsar la reforma del sistema económico para eliminar el despilfarro y hacerlo «eficiente». Posteriormente, los Webb no dejarían de ocultar su gran admiración por la «eficiencia» que creen observar en la Rusia soviética, hasta el punto de que Beatriz manifestó que «llegó a enamorarse del comunismo soviético».

Otro autor destacado que cayó en las redes de la concepción estática de la eficiencia económica es el propio John Maynard Keynes, que en su introducción a la versión alemana de la Teoría General, publicada en 1936, indica expresamente cómo sus prescripciones de política económica «son más fácilmente adaptables a las condiciones de un Estado totalitario». Keynes además alabó sin reservas el libro Soviet Communism que los Webb habían publicado en $1933 .{ }^{17}$

\section{c) El concepto estático de eficiencia y la «economía del bienestar»}

La evolución descrita en el epígrafe anterior culmina a partir de los años 20 y 30 del siglo pasado en los que el concepto estático de eficiencia económica se convierte en el centro focal de investigación ${ }^{18}$ en torno al cual se desarrolla toda una nueva disciplina

17 "Are more easily adapted to the conditions of a totalitarian state», Keynes (1973), vol. VII, p. XXVI; y vol. XXVIII, pp. 333-334. Keynes igualmente se hizo eco de aquellas afirmaciones de los intelectuales que quedaron obnubilados por los triunfos económicos de la Unión Soviética («he ido al futuro y funciona»). Véase también Ralph Raico (1997).

18 Véase infra, p. 11ss. 
que termina denominándose «economía del bienestar» y que se elabora sobre la base de una serie de enfoques alternativos.

Así, según el enfoque pigoviano, la eficiencia máxima del sistema económico se alcanzaría cuando se igualasen las utilidades marginales de todos los factores, para lo cual sería preciso redistribuir la renta hasta que la última unidad monetaria de cada actor le proporcionase a cada uno la misma utilidad marginal. Pigou culmina así la tradición del estrecho utilitarismo, que se había iniciado con Jeremías Bentham y que después sería continuada por los marginalistas ingenuos (Sax, Sidgwick, etc.). Obviamente, el enfoque de Pigou implica efectuar comparaciones interpersonales de utilidad e introducir juicios de valor metacientíficos, por lo que fue pronto sustituido con carácter general por el alternativo enfoque paretiano.

Según el enfoque paretiano, un sistema económico se encuentra en una situación de eficiencia si no es posible mejorar a alguien sin empeorar a otro. Este enfoque, aunque sigue siendo esencialmente estático, evitó aparentemente la necesidad de efectuar comparaciones interpersonales de utilidad y abrió el camino para que diversos cultivadores de la economía del bienestar (Lerner, etc.) articulasen el denominado "primer teorema de la economía del bienestar», según el cual el sistema de competencia perfecta consigue una asignación eficiente en sentido paretiano. El paso siguiente consistió en identificar una serie de «fallos del mercado» que supuestamente generarían ineficiencias (en sentido estático) al alejar el sistema económico del modelo de «competencia perfecta» (así, se habla, en un primer momento, de los casos de monopolio y los efectos externos, para después analizar situaciones más sofisticadas de ineficiencia estática, como pueden ser las de información asimétrica, riesgo moral o moral hazard, mercados incompletos, etc.). Paralelamente, y con carácter alternativo, se propone el enfoque de KaldorHicks, mediante el cual se introduce el principio analítico de la «compensación potencial»: la situación II se considera más efi- 
ciente que la I si aquellos que ganan pueden compensar a los que pierden (Kaldor); o si los que pierden con la II no pueden «sobornar» para que no hagan el cambio a los que ganan con el paso de la I a la II (Hicks). ${ }^{19}$

Posteriormente, se articula el «segundo teorema fundamental de la economía del bienestar», según el cual la eficiencia paretiana sería compatible con diversos estados de dotaciones iniciales. Este teorema implica considerar que los criterios de eficiencia y equidad son aislables y pueden combinarse en diferentes proporciones. Bergson y Samuelson, por su parte, introducen la «función de bienestar social» que, aunque cae de nuevo en las comparaciones interpersonales de utilidad, permitiría eliminar la indeterminación del punto de eficiencia máxima entre todos los que son paretoeficientes y que constituyen la curva de posibilidades máximas de producción.

Sin embargo, más tarde Arrow demostraría que es imposible obtener una función de bienestar social que satisfaga una serie de condiciones de coherencia bastante razonables («tercer teorema fundamental de la economía del bienestar»). Y otro Premio Nobel de Economía, Amartya K. Sen, también demostrará, en la misma línea, que es imposible concebir una función de bienestar social que simultáneamente cumpla el óptimo de Pareto y los criterios tradicionales del liberalismo, básicamente porque no se pueden «agregar» los rankings individuales de utilidad ordinal, por lo que no es posible dar solución a través de la función del bienestar social a todas las preferencias individuales. ${ }^{20}$

${ }^{19}$ Sobre la imposibilidad práctica, en todo caso, de aplicar el criterio de KaldorHicks, debe consultarse el artículo de Stringham (2001), pp. 41-50.

20 Véase el resumen sobre el estado de la cuestión de Gámir (1996). 
d) Críticas a la economía del bienestar y a su concepto de eficiencia estática

Obviamente, no podemos referirnos con detalle a todas las críticas que se han expuesto en contra de los diferentes criterios de eficiencia estática que han surgido en el ámbito de la economía del bienestar. Estos enfoques ya han sido analizados críticamente en una amplia literatura que aquí no podemos reproducir. No obstante, haremos un resumen de las críticas más comunes, sobre todo con la finalidad de contrastarlas con la que, en nuestra opinión, es con mucho la crítica más importante y que ha permanecido hasta ahora prácticamente relegada al olvido.

Así, en primer lugar, los diferentes criterios de eficiencia estática utilizados al amparo de la economía del bienestar implican la introducción más o menos subrepticia de juicios de valor que carecen de objetividad científica. Esto es evidente, como ya se ha indicado, en el caso de los enfoques de Pigou y de la función de bienestar social, pues ambos exigen efectuar, para tener un contenido operativo, comparaciones interpersonales de utilidad, científicamente ilegítimas según el consenso alcanzado por la mayoría de los economistas desde Lionel Robbins. Es más, tampoco está del todo claro que puedan efectuarse comparaciones de utilidad por parte de un mismo individuo y en relación consigo mismo, si es que se refieren a momentos distintos del tiempo y en el contexto de acciones diferentes, pues en este caso, y aun tratándose de la misma persona, se estaría intentando comparar dimensiones en muchos casos distintas y heterogéneas, difícilmente comparables entre sí. Por otro lado, incluso el enfoque paretiano, y a pesar de las apariencias, tampoco se podría considerar completamente neutro desde el punto de vista de las comparaciones interpersonales de juicios de valor: un envidioso, por ejemplo, podría sentirse realmente peor si es que se produjera una mejora paretiana (en la que alguien saliese ganando sin empeorar «aparentemente» a nadie, salvo, por supuesto, al propio envidioso). 
En segundo lugar, los distintos enfoques de la economía del bienestar adolecen del importante defecto de suponer que los rankings individuales de utilidad y las diferentes alternativas que se abren a cada actor están «dados», es decir, son conocidos y no cambian. $\mathrm{O}$, expresado de otra manera, en ellos se supone siempre que existen «funciones de utilidad», y que éstas son constantes y se conocen. Este supuesto es especialmente restrictivo y criticable en el caso del enfoque pigoviano, cuya propuesta normativa de redistribuir la renta, no sólo implica efectuar comparaciones interpersonales de utilidad, sino que, además, su implementación práctica daría lugar a un cambio radical en las correspondientes «funciones de utilidad», y también, y esto es aún mucho más importante como luego veremos, afectaría completamente al proceso empresarial de coordinación.

En tercer lugar, los criterios de eficiencia estática siguen muy influidos por el concepto de eficiencia técnica procedente del campo de la física mecánica. Y ello a pesar de todos los esfuerzos realizados por muy distinguidos economistas (Robbins, Lipsey, Alchian y Allen, etc.) por tratar de distinguir de una vez por todas entre la eficiencia técnica o tecnológica y la eficiencia económica. ${ }^{21}$ Así, se ha argumentado que mientras la eficiencia técnica o tecnológica consistiría en minimizar la utilización de inputs en términos físicos (por ejemplo, toneladas de carbón, barriles de petróleo, etc.) para lograr un determinado resultado, la eficiencia económica consistiría en lo mismo, es decir, en la minimización de la utilización de inputs, pero no en términos físicos, sino en términos de coste (es decir, unidades de input multiplicadas por su precio de mercado). Ahora bien, si se supone, como se hace en todos los criterios de eficiencia estática mencionados, que las tecnologías y los precios de mercado están «dados», es decir, que se conocen y no varían, entonces es evi-

${ }^{21}$ Robbins (1972), pp. 36-37; Lipsey (1973), pp. 222-224; Alchian y Allen (1964), pp. $435-437$. 
dente que el modus operandi de la eficiencia económica (en su versión estática) y el de la eficiencia técnica serían idénticos: ambos consistirían en una mera operación matemática de maximización sometida a restricciones conocidas. Puede concluirse, por tanto, que en el contexto de la economía del bienestar existe una plena similitud formal entre el concepto de eficiencia técnica y el concepto estático de eficiencia económica. $\mathrm{O}$, expresado de otra forma: la concepción estática de la economía reduce el concepto de eficiencia económica a un mero problema técnico de maximización, que en todo caso podría solucionarse con un simple ordenador al que se le introdujeran los datos que siempre se suponen conocidos en los modelos de eficiencia estática. ${ }^{22}$

Sin embargo, y a pesar de la relevancia de las anteriores críticas, las mismas no tocan de lleno a la que nosotros consideramos que constituye la crítica fundamental que hay que hacer a los diferentes criterios de eficiencia propuestos en el ámbito de la economía del bienestar. Y es que éstos tan sólo se fijan en uno de los dos aspectos que tiene el concepto de eficiencia económica. Es decir, se centran exclusivamente en la dimensión estática de la eficiencia económica, en la que se supone, en primer lugar, que los recursos están dados y no cambian y, en segundo lugar, que el problema económico fundamental consiste en evitar el despilfarro de los mismos, sin tener en cuenta para nada, a la hora de enjuiciar, por ejemplo, una empresa, una institución social o todo un sistema económico, su eficiencia dinámica, entendida como la capacidad para impulsar, por un lado, la creatividad empresarial y, por otro lado, la coordinación, es decir, la capacidad empresarial para buscar, descubrir y superar los diferentes desajustes sociales.

$\mathrm{Y}$ es que, en nuestra opinión, lo verdaderamente relevante, más que llevar el sistema hacia la frontera de posibilidades máxi-

22 Posteriormente a haber escrito este artículo me he dado cuenta de que Buchanan sugiere la misma idea en Buchanan (1979), p. 25. 
mas de producción (considerando «dada» la correspondiente curva), consiste en aplicar sistemáticamente el criterio de eficiencia dinámica, que es aquel que se fija en la capacidad del sistema para «mover» continuamente hacia la derecha la curva de posibilidades máximas de producción. De ahí la importancia de completar y superar los tradicionales criterios estáticos de eficiencia económica con un criterio alternativo que sea capaz de recoger la dimensión dinámica que tiene todo sistema económico. En el apartado siguiente vamos a estudiar, con más detalle, el criterio de eficiencia dinámica que estamos proponiendo.

\section{El concepto económico de eficiencia dinámica}

\section{a) La eficiencia dinámica y la función empresarial}

El criterio de eficiencia dinámica está indisolublemente unido al concepto de función empresarial y, de hecho, la plena comprensión del concepto económico de eficiencia dinámica que vamos a presentar exige que, con carácter previo, repasemos, siquiera sea brevemente, cuáles son el concepto y las características básicas de la función empresarial, entendida como la principal impulsora de la creatividad y de la coordinación que surgen espontáneamente en el mercado.

El término «función empresarial» $\mathrm{o}$ «empresarialidad» etimológicamente procede del latín in prehendo, que significa «descubrir», «ver», «darse cuenta» de algo. En este sentido podemos definir la función empresarial como la capacidad típicamente humana para darse cuenta de las oportunidades de ganancia que surgen en el entorno actuando en consecuencia para aprovecharse de las mismas. La función empresarial implica, por tanto, una especial perspicacia, que el Diccionario de nuestra Real Academia define como la «vista o mirada muy aguda y que alcanza mucho». También es plenamente aplicable a la idea de empresarialidad que estamos explicando el término especular, que etimológicamente tam- 
bién procede del latín, en este caso del término specula, que se utilizaba para designar a las torres desde las que los vigías podían ver a distancia lo que iba a venir. ${ }^{23}$

Las características más importantes del concepto de función empresarial que acabamos de introducir, cara al criterio de eficiencia dinámica que estamos estudiando, son las siguientes.

En primer lugar, la función empresarial siempre genera nueva información, es decir, todo acto empresarial supone el descubrimiento de una información nueva que antes no tenía el actor (una oportunidad de ganancia que previamente había pasado inadvertida). Esta información que constantemente crean los empresarios cuando actúan es subjetiva, práctica (en el sentido de que sólo se crea mediante el ejercicio de la acción empresarial en sus correspondientes contextos), dispersa (pues está diseminada en la mente de todos los seres humanos) y tácita (en el sentido de que es muy difícilmente articulable de manera formalizada).

En segundo lugar, la función empresarial, por su propia naturaleza, es esencialmente creativa. Significa ello que todo desajuste social se plasma en una oportunidad de ganancia que queda latente para ser descubierta por los empresarios. Así, por ejemplo, si B no valora y utiliza mal un recurso R que es altamente necesitado por A, es obvio que ello implica la existencia de un desajuste social que da lugar a una oportunidad de ganancia: basta que un empresario $C$ se dé cuenta de ese desajuste, para que compre barato el recurso a B y se lo venda caro a A, obteniendo de esta manera un «beneficio empresarial puro». Por tanto, cuando un empresario se da cuenta de una oportunidad de ganancia que previamente había pasado inadvertida, crea una información en su mente que antes no existía, que resulta, una vez se lleva a cabo el acto empresarial, en la obtención de un beneficio empresarial puro.

${ }^{23}$ Sobre la teoría de la función empresarial y sus más importantes elementos y características puede consultarse Huerta de Soto (2001) (b), capítulo 2. 
En tercer lugar, la función empresarial transmite información. En efecto, si un empresario $C$ compra barato a $B$ un recurso $R$ que tiene en abundancia y malutiliza, para vendérselo caro a $\mathrm{A}$, que lo necesita con urgencia, transmite a A y B la información de que el recurso $\mathrm{R}$ está disponible y debe guardarse, y a todo el mercado, en oleadas sucesivas, que alguien está dispuesto a pagar por $\mathrm{R}$ un buen precio de mercado (los precios de mercado son señales muy potentes en el sentido de que transmiten mucha información a un coste muy reducido).

En cuarto lugar, la función empresarial es coordinadora. Como consecuencia del acto empresarial que venimos describiendo, A y B aprenden a disciplinar o coordinar su comportamiento en función de las necesidades ajenas del otro: en efecto, una vez el desajuste social se ha descubierto y es eliminado, B guarda el recurso $\mathrm{R}$ que antes no utilizaba y lo guarda para entregárselo a $A$, que lo necesita con urgencia.

En quinto lugar, la función empresarial es competitiva. El término competencia procede del latín cum petitio que significa concurrencia múltiple de peticiones sobre la misma cosa a la que hay que adjudicar un dueño. La empresarialidad es competitiva precisamente en el sentido de que, una vez descubierta o creada y aprovechada la oportunidad de ganancia por un determinado empresario, esa misma oportunidad de ganancia, con sus coordenadas específicas de tiempo y lugar, ya no puede ser creada, descubierta y aprovechada por otro empresario. Esto hace que el proceso empresarial sea, ante todo, un proceso de rivalidad, netamente competitivo, en el que los empresarios rivalizan unos con otros por descubrir antes que nadie y aprovecharse antes que los demás, de las oportunidades de ganancia que se van generando en su entorno. De ahí que sea muy precisa la definición de competencia dada en el Diccionario de nuestra Real Academia cuando se refiere a la misma como «la rivalidad entre dos o más que aspiran a obtener la misma cosa». El concepto de competencia que hemos presentado obviamente nada tiene que 
ver con el denominado "modelo de competencia perfecta», en el que múltiples oferentes hacen lo mismo y venden el mismo bien al mismo precio, es decir, en el que, paradójicamente, no puede considerarse que nadie compita.

Por último, en sexto lugar, el proceso empresarial jamás se detiene ni agota. Aunque podría pensarse que el proceso social impulsado por la empresarialidad podría llegar a una situación de equilibrio, es decir, a detenerse o agotarse una vez que se descubrieran y aprovecharan por los empresarios todas las oportunidades de ganancia en las que se plasman los desajustes sociales (y, de hecho, tal «estado final de reposo» es el que, con carácter prioritario, se considera como único objeto de estudio que merece la pena investigar por parte de la mayoría de los miembros de nuestra profesión), no cabe considerar que el proceso empresarial de coordinación jamás se detenga o agote. Y es que el acto empresarial, a la vez que coordina, crea nueva información que a su vez modifica en el mercado la percepción general de fines y medios de los actores implicados, lo cual da lugar a la aparición de nuevos desajustes, que a su vez tienden a ser descubiertos y coordinados empresarialmente, y así sucesivamente a lo largo de un proceso que jamás se detiene de expansión sin límite del conocimiento y los recursos, apoyado sobre un volumen de población siempre creciente, y que tiende a ser tan coordinado como sea humanamente posible en cada circunstancia histórica («Big Bang social coordinado»).

Explicadas las características esenciales del proceso empresarial, nos encontramos ya en disposición de poder entender mejor el concepto económico de eficiencia dinámica que vamos a presentar, así como la posición de los diferentes autores que en la historia del pensamiento económico han venido aproximándose al mismo. 
b) El concepto económico de eficiencia dinámica: creatividad y coordinación

En un sentido dinámico, puede afirmarse que, por ejemplo, un ser humano, una empresa, una institución, o todo un sistema económico, serán tanto más eficientes conforme más y mejor impulsen la creatividad y la coordinación empresarial, tal y como las acabamos de explicar.

En esta perspectiva dinámica, lo verdaderamente importante no es tanto el evitar el despilfarro de unos medios que se consideran conocidos y «dados» (objetivo que, recordemos, era el prioritario en la perspectiva de la eficiencia estática) como el descubrir y crear continuamente nuevos fines y medios, impulsando la coordinación y asumiendo que en todo proceso empresarial siempre surgirán nuevos desajustes, por lo que un cierto despilfarro es inevitable y consustancial a toda economía de mercado.

En este sentido, puede considerarse que la dimensión dinámica de la eficiencia es la más relevante, pues, de hecho, aunque un sistema económico no se encuentre en la frontera de posibilidades máximas de producción, es posible que todos sus agentes salgan ganando si es que la creatividad empresarial mueve constantemente la curva hacia fuera aumentando, así, las posibilidades de todos, gracias a un flujo continuo de creatividad de nuevos fines y medios que, hasta su descubrimiento empresarial, previamente ni siquiera habían podido ser concebidos por nadie.

Por otro lado, y esto es muy relevante, puede considerarse que la dimensión dinámica engloba a la dimensión estática de la eficiencia económica, pues precisamente es la misma fuerza de la función empresarial que induce la eficiencia dinámica cuando crea y descubre nuevas oportunidades de ganancia la que logra el máximo grado de eficiencia estática que sea humanamente posible en cada momento, al coordinar los desajustes preexistentes (aunque, dado el flujo inacabable de nuevos desajustes, nunca pueda concebirse, 
como ya hemos indicado, que sea posible alcanzar el óptimo paretiano en una economía real de mercado y que, por tanto, se elimine totalmente el posible despilfarro de los recursos existentes).

A continuación vamos a comentar las aportaciones de diversos autores que se han aproximado, en una u otra perspectiva, al concepto de eficiencia dinámica que acabamos de exponer. No es de extrañar que muchos de estos autores estén muy influidos por la tradición de la Escuela Austriaca de Economía que, si por algo se caracteriza, es precisamente por el acento que pone en la concepción dinámica del mercado y en el papel protagonista que en sus procesos tiene la función empresarial. En este sentido, deberían darse por reproducidos aquí los trabajos más importantes de Mises y Hayek sobre el mercado, entendido como un proceso dinámico impulsado por la empresarialidad (Mises) y sobre la competencia entendida como un proceso de descubrimiento (Hayek). ${ }^{24}$

\section{c) Israel M. Kirzner y el concepto de eficiencia dinámica}

Kirzner es el gran pensador contemporáneo sobre la función empresarial cuyo análisis ha desarrollado in extenso siguiendo el liderazgo iniciado por Mises y Hayek. Ha de considerársele también como uno de los teóricos más relevantes que han estudiado el concepto económico de eficiencia dinámica, que define como «la capacidad para impulsar la perspicacia y el descubrimiento empresarial de un conocimiento que previamente no se concebía que se podía adquirir». Según Kirzner, el acto empresarial es eminentemente coordinador, entendiendo la coordinación social no en su sentido estático o paretiano, sino en su sentido dinámico, es decir, «como un proceso en el que los participantes del mercado se dan cuenta de oportunidades de ganan-

\footnotetext{
${ }^{24}$ Huerta de Soto (2001) (a), capítulos 5 y 6.
} 
cia mutuamente beneficiosas que, una vez aprovechadas, ajustan múltiples errores previos». ${ }^{25}$

Además, Kirzner se ha cuidado de señalar que el criterio de eficiencia dinámica que propone, basado en la creatividad y en la coordinación empresarial, está libre de todo juicio de valor, por lo que es plenamente wertfrei: en efecto, quien desee impulsar la coordinación sabe que ha de favorecer y fomentar la función empresarial libre; quien, por el contrario, valore más los desajustes y conflictos sociales, deberá poner todo tipo de trabas a la función empresarial. ${ }^{26}$ La teoría económica, por sí sola, no puede calificar como bueno o malo uno u otro fin, si bien indudablemente ayuda a que los seres humanos vean más claramente las alternativas éticas y puedan tomar más fácilmente una posición moral coherente.

La eficiencia dinámica, tal y como Kirzner la concibe, es inmune al conjunto de las críticas que acabamos de exponer en relación con los diferentes criterios de eficiencia estática que hasta ahora han preponderado. Finalmente, Kirzner señala cómo, desde el punto de vista analítico, la dimensión dinámica es especialmente útil para efectuar análisis comparativos de las distintas instituciones y de las diferentes alternativas de legislación. Y es que el análisis de la eficiencia dinámica permite efectuar una evaluación y llevar a cabo una toma de posición mucho más clara y en múltiples ocasiones muy distinta de la que habitualmente se deduce del simple análisis efectuado exclusivamente en términos de eficiencia estática. ${ }^{27}$

\footnotetext{
25 Kirzner (1997), p. 67.

26 Kirzner, (1998), pp. 187-200.

27 Israel M. Kirzner (1997), p. 64.
} 
d) Murray N. Rothbard y el mito de la eficiencia estática. El intento de sintesis de Roy E. Cordato

Las aportaciones de Rothbard en el campo del análisis de la eficiencia dinámica son también importantes. Por un lado, este autor ha insistido en que el ideal de "eficiencia estática», estudiado con carácter dominante por los teóricos de la economía del bienestar, no es sino un mito, pues exige para su manejo operativo un marco dado de fines y medios que nunca puede llegar a existir, ni mucho menos a conocerse, en una realidad social constantemente cambiante. Además, Rothbard es quizás el autor que más claramente ha expuesto la conexión que existe entre la concepción dinámica de la eficiencia económica y el ámbito de la ética. Rothbard considera imprescindible, dado el desconocimiento respecto de los fines, medios y funciones de utilidad que existen en la realidad, establecer con carácter previo el marco ético adecuado que impulse la eficiencia dinámica. Este marco está constituido por el conjunto de normas que regulan el derecho de propiedad y hacen posible el intercambio voluntario en el que los diferentes agentes económicos siempre demuestran cuáles son sus preferencias verdaderas. Para Rothbard, sólo los principios éticos pueden servir como criterio de eficiencia a la hora de tomar decisiones. ${ }^{28}$

Roy E. Cordato, en un libro interesante, ha analizado desde el punto de vista de la economía del bienestar las principales aportaciones de los economistas austriacos en general y las de Mises, Rothbard, Hayek y Kirzner, en particular, llegando a la conclusión de que lo importante en el mercado, más que lograr resultados «óptimos» (objetivo de la dimensión estática de la eficiencia), es que prepondere un marco institucional adecuado que favorezca el descubrimiento empresarial y la coordinación. La política económica ha de orientarse a identificar y remover

${ }_{28}$ Rothbard (1979), p. 95; y Rothbard (1997), pp. 211-254. 
las trabas artificiales que dificultan los intercambios voluntarios y el proceso empresarial. ${ }^{29} \mathrm{El}$ intento de Cordato es especialmente meritorio en la medida en que tiene por objetivo abrir las ventanas de la ya rancia economía del bienestar, hasta ahora anclada en presupuestos exclusivamente estáticos, a la concepción subjetivista y dinámica del mercado que, con carácter prioritario, ha sido hasta ahora desarrollada casi exclusivamente bajo el liderazgo de los teóricos de la Escuela Austriaca.

\section{e) Joseph Alois Schumpeter y el «proceso de destrucción creadora»}

Quizás uno de los autores popularmente más conocidos a la hora de aplicar una peculiar concepción de la dimensión dinámica al análisis de la eficiencia económica sea Joseph Alois Schumpeter. Schumpeter inicia su programa de investigación en este ámbito ya en 1911 cuando publica la primera edición alemana de su Teoría del desenvolvimiento económico. ${ }^{30}$ En este libro Schumpeter ya se refiere, siguiendo una línea de investigación netamente austriaca, al empresario innovador, que para Schumpeter es aquel que concibe y descubre nuevos bienes, combinaciones de bienes, fuentes de aprovisionamiento, introduce innovaciones tecnológicas y continuamente crea nuevos mercados y amplía los ya existentes. Treinta años después, en 1942, Schumpeter continúa esta misma línea de investigación en su libro Capitalismo, socialismo y democracia, especialmente en sus capítulos 7 y 8 . Este último capítulo incluso se titula por el autor «El proceso de destrucción creadora», y en él se explica el proceso de evolución económica que ha dado lugar al desarrollo del capitalismo, introduciéndose ya la tensión inherente a las dos dimensiones del concepto de eficiencia, la dinámica y la estática. Schumpeter es muy crítico con el concepto tradicional de eficiencia estática utilizado por la

\footnotetext{
29 Cordato (1992).

30 Schumpeter (1944), especialmente p. 135 y ss.
} 
economía neoclásica y concluye que «la competencia perfecta no sólo es imposible, sino inferior, y carece de todo título para ser presentada como modelo de eficiencia ideal». ${ }^{31}$

Nuestra principal crítica a Schumpeter es que siga considerando que el punto básico de referencia del análisis económico debe ser el modelo de equilibrio, pues cree que el mundo económico, si no fuera por los empresarios, se encontraría «normalmente» en una situación de flujo rutinario. Schumpeter concibe, pues, que el empresario no es sino un elemento exclusivamente distorsionador o desequilibrador. Es decir, tan sólo se fija en una de las facetas del proceso empresarial, en aquella que ha denominado con la expresión ya consagrada de «proceso de destrucción creadora». Schumpeter ignora que, según ya hemos expuesto en apartados anteriores, el centro focal de investigación del análisis económico ha de ser el proceso dinámico empresarial y no el modelo de equilibrio. Y es que el proceso de mercado real impulsado por la empresarialidad posee, con carácter simultáneo, no sólo una capacidad de «destrucción creadora», que es a la que con carácter exclusivo se refiere Schumpeter, sino también una capacidad eminentemente coordinadora, que tiende a llevar el proceso social hacia un equilibrio que, sin embargo, nunca se alcanza, puesto que en su camino de coordinación surgen continuamente nuevos desajustes. Para Schumpeter el proceso empresarial es una especie de fuerza explosiva que, como resultado de la creatividad empresarial, distorsiona el orden preexistente, sin darse cuenta de que la misma fuerza que impulsa la destrucción creadora tiende a coordinar el sistema haciendo que el «big bang» social sea tan armonioso como sea posible en cada circuns-

31 Schumpeter (1971), capítulo 8, p. 149. La cita en inglés de Schumpeter es la siguiente: «Perfect competition is not only impossible but inferior and has no title to being set up us a model of ideal efficiency.» Capitalism, Socialism and Democracy, Harper Perennial, Nueva York 1976, p. 106 (primera edición publicada por Harper and Brothers en 1942). Blaug (1998), p. 7 ha utilizado expresamente el término «eficiencia dinámica» para referirse al punto de vista de Schumpeter. 
tancia histórica. Por tanto, frente a Schumpeter, que considera al empresario como un elemento exclusivamente desequilibrador, el enfoque de eficiencia dinámica que estamos proponiendo parte de considerar la empresarialidad como una fuerza impulsora, simultáneamente creativa y coordinadora, que continuamente hace avanzar el mercado y la civilización.

\section{f) El concepto de Eficiencia-X de Harvey Leibenstein}

Harvey Leibenstein introdujo por primera vez el concepto de eficiencia-X en su artículo "Allocative efficiency vs. Xefficiency», publicado en $1966 .{ }^{32}$ En este trabajo Leibenstein concibe la ineficiencia- $X$ como el grado de ineficiencia que surge en el mercado como consecuencia del carácter incompleto que tienen muchos de los contratos que regulan las relaciones empresariales, sobre todo porque no precisan bien las tareas que cada uno debe realizar. También señala como fuentes de ineficiencia la presión psicológica a que se ven sometidos los diferentes agentes económicos, y el peso de los hábitos, inercias y rutinas que hacen que muchas labores cuyo resultado podría mejorarse permanezcan indefinidamente en una situación de ineficiencia.

Es de resaltar, ante todo, el carácter bastante equívoco del concepto de ineficiencia- $X$ que propone Leibenstein, al menos en sus primeras formulaciones. Parece como si Leibenstein hubiera intuido una idea importante (que existe una ineficiencia que pasa inadvertida en los modelos de equilibrio) que, sin embargo, no es capaz de articular con total claridad. Ello dio pie a que, diez años después, Stigler (1976), en un artículo irónicamente titulado "The Existence of X-Efficiency», ${ }^{33}$ contestara a Leibenstein que, en todo caso, la cantidad de ignorancia e inercia que pueda existir en el mercado será siempre óptima, pues el

\footnotetext{
32 Leibenstein (1966), pp. 392 a 415.

33 Stigler (1976), pp. 213-216.
} 
esfuerzo destinado a tratar de superarlas se detendrá justo cuando el coste marginal derivado del mismo empiece a superar al ingreso marginal esperado. Kirzner salió posteriormente en apoyo de Leibenstein argumentando que, al menos, siempre existirá una importante fuente de ineficiencia-X: aquella consistente en el error empresarial genuino, que surge precisamente cuando a alguien le pasa inadvertida una oportunidad de ganancia en el mercado, que queda así latente para ser descubierta y aprovechada en el futuro por otros empresarios. ${ }^{34}$

Es decir, el argumento básico de Kirzner en relación con la eficiencia-X es el de que, reconociendo que ésta no existe, por definición, en un entorno de equilibrio y plena información (éste, y no otro, era el argumento claramente irrelevante de Stigler), la única posibilidad de que el concepto de eficiencia- $X$ pueda mantenerse con un sentido analítico y operativo, consiste en identificarlo con el concepto de eficiencia dinámica que hemos expuesto, idea ésta que, en última instancia, parece que ha terminado siendo aceptada por el propio Leibenstein. Y es curioso constatar cómo «el padre de la criatura», Harvey Leibenstein, se ha visto forzado a admitir que su concepto de eficiencia- $X$, tan confusa y vagamente definido en un principio, sólo mantiene un (elevado) grado de relevancia, depurándose de sus vaguedades y equívocos iniciales, si es que tiende a identificarse con el concepto de eficiencia dinámica tal y como ya lo hemos definido en el presente trabajo. ${ }^{35}$

\section{g) El concepto de «eficiencia adaptativa» de Douglas C. North}

El Premio Nobel de Economía Douglas C. North ha criticado el concepto paretiano de eficiencia meramente asignativa que utilizan con carácter predominante los economistas neoclásicos, ofreciendo como alternativa el concepto de eficiencia adaptativa

\footnotetext{
34 Kirzner (1979), pp. 120-136.

35 Sobre la eficiencia-X puede consultarse además el libro de Frantz (1988).
} 
que define como «la capacidad de la sociedad para adquirir conocimiento, aprender, inducir la innovación, fomentar la creatividad y la asunción de riesgos, y resolver cuellos de botella a lo largo del tiempo». ${ }^{36}$

Como se ve, North menciona en esta definición una serie de características que son plenamente coincidentes con las que ya se han analizado como propias del concepto de eficiencia dinámica: la adquisición de conocimiento, la creatividad, la innovación, etc. Además, y esto quizás sea lo más característico de North, este autor se fija especialmente en el marco institucional de normas que fomentan la creatividad y la capacidad de adaptarse de las diferentes sociedades, poniendo como modelos históricos de flexibilidad y capacidad de adaptación a las sociedades europea y norteamericana.

Nuestra principal crítica a Douglas C. North es que no menciona expresamente la función empresarial como la fuerza protagonista que impulsa todos los procesos de mercado. Es decir, North se centra casi exclusivamente en analizar la capacidad de las sociedades en general para adaptarse a los cambios y shocks «externos» que les afectan y supuestamente siempre proceden de fuera y, precisamente por ello, propone utilizar el término de «eficiencia adaptativa». El enfoque de North es, por tanto, mucho más reactivo que proactivo. En efecto, North parece no darse cuenta de que es precisamente el impulso empresarial que caracteriza a la eficiencia dinámica y a su capacidad coordinadora el que, también y simultáneamente, induce los cambios o shocks (por tanto no externos sino endógenos) que generan los problemas ante los que deben adaptarse las diferentes sociedades.

Es evidente, por tanto, que North cae en el extremo contrario al de Schumpeter. Es decir, mientras Schumpeter se fijaba con

36 North (1990), pp. 80-82, 99 y 136; y North (1999), pp. 17-18. La mejor evaluación crítica de North, desde el punto de vista austriaco, ha sido escrita por Stromberg, (2002), pp. 101-137. 
carácter exclusivo en la dimensión de la creatividad empresarial y en su capacidad destructora (proceso de «destrucción creadora»), North se fija en la otra dimensión, es decir, en la capacidad adaptativa o coordinadora de la función empresarial, olvidándose, por completo, de la faceta simultáneamente creadora que siempre tiene la misma. En este sentido puede considerarse que la teoría de la eficiencia dinámica impulsada por la empresarialidad que se ha presentado en este trabajo combina adecuadamente las dos dimensiones (la creativa y la coordinadora), que de forma separada, excluyente y reduccionista han estudiado parcialmente Schumpeter y North.

h) El concepto de eficiencia dinámica y la teoría de los costes de transacción de Ronald H. Coase

Parece ahora pertinente hacer algunos comentarios sobre las relaciones que puedan existir entre el concepto de eficiencia dinámica que hemos explicado y la teoría de los costes de transacción que tiene su origen en Ronald H. Coase, y que tanto predicamento ha alcanzado en muchos ámbitos del análisis económico, especialmente del derecho y de las instituciones. ${ }^{37}$

Quizá la diferencia esencial entre ambos enfoques sea la señalada por Israel Kirzner. Para este autor, el obstáculo básico que dificulta la eficiencia dinámica no lo plantean los costes de transacción, sino lo que él denomina el «error empresarial puro o genuino», que es aquel que surge en el mercado cuando falta la suficiente perspicacia empresarial. ${ }^{38} \mathrm{O}$, expresado de otra forma, aunque pudiéramos concebir un hipotético nirvana ${ }^{39} \mathrm{O}$ «mundo

37 Véase, por ejemplo, entre los tratamientos más recientes, el de Zerbe (2001).

38 Kirzner (1973) pp. 225-234. Existe una traducción española publicada en su segunda edición por Unión Editorial en 1998 con el título de Competencia y empresarialidad, Madrid 1998, pp. 237-246.

39 Harold Demsetz ha criticado el Nirwana approach de muchos economistas neoclásicos (Arrow, etc.) que se empeñan en comparar instituciones reales con instituciones ideales que jamás pueden darse en la realidad, pues los costes de tran- 
ideal con costes de transacción cero», tal sistema no lograría el ideal de eficiencia dinámica si, por culpa de errores empresariales puros o genuinos, quedaran múltiples oportunidades de ganancia sin descubrir, crear y aprovechar. Y es que, en última instancia, y a pesar de las apariencias, el enfoque de los costes de transacción sigue adoleciendo de muchas de las carencias que ya analizamos en relación con la dimensión estática de la eficiencia. En concreto, efectuar un análisis de comparativa institucional centrándose en los diferentes costes de transacción de cada institución, implica el suponer que éstos están dados y son conocidos, y que es incluso posible efectuar un rediseño institucional que permita modificar los costes de transacción de cada situación dada. Sin embargo, todo el marco de costes de transacción que se tome como referencia en el análisis puede cambiar de forma radical e imprevista si, como consecuencia de un acto de pura creatividad empresarial, se descubren nuevas alternativas, posibilidades de producción y, en general, nuevas soluciones a los problemas que, hasta ese momento, previamente habían pasado completamente inadvertidos a los empresarios.

Por eso, y en la óptica de la eficiencia dinámica, tal y como veremos con detalle más adelante, al basarse ésta en la creatividad y en la coordinación empresarial, nunca puede ser irrelevante la distribución inicial de derechos de propiedad (incluso, como erróneamente supone el Teorema de Coase, en el caso extremo de que los costes de transacción sean nulos). Y es que la distribución de derechos de propiedad, enmarcada en el esquema ético que hace posible la eficiencia dinámica y que analizaremos después, es precisamente la que determina, en cada circunstancia específica de tiempo y lugar, quién sentirá los incentivos con-

sacción que implicaría el llevar el sistema real al «nirvana» serían imposibles de superar. El esquema de Demsetz, aunque nos parezca un meritorio paso adelante en el realismo del análisis, no es sin embargo completamente adecuado, pues sigue ignorando que el problema esencial, más que de costes de transacción, es de naturaleza netamente empresarial. Véase Demsetz (1989), capítulo 1, pp. 3-24. 
cretos que son necesarios para despertar el acto empresarial, con su doble dimensión creativa y coordinadora. $\mathrm{O}$, expresado de otra manera, en la óptica de la eficiencia dinámica basada en la función empresarial, el denominado Teorema de Coase, con independencia de cuál sea la interpretación concreta que al mismo se dé, es científicamente falso, pues ni siquiera en un supuesto esquema institucional con costes de transacción cero la distribución de derechos de propiedad será irrelevante cara a alcanzar el objetivo de la eficiencia dinámica. ${ }^{40}$

i) El concepto de eficiencia dinámica en los libros de texto de Economía

La dimensión dinámica del concepto de eficiencia económica es prácticamente ignorada por la mayoría de los libros de texto de nuestra disciplina. Esto, a su vez, es una ilustración más de la obsesión que por la estática comparativa y el modelo de equilibrio hasta ahora ha preponderado en la ciencia económica y, por tanto, de la urgencia de impulsar un cambio de paradigma que dé entrada al análisis dinámico de los mercados y al concepto de eficiencia dinámica.

En una muestra de veinte manuales, seleccionados de entre los más conocidos en lengua inglesa y española en el ámbito de la economía, tan sólo en cuatro de ellos se menciona explícitamente al concepto de eficiencia dinámica. Y en la mayoría de estas honrosas excepciones el tratamiento del concepto es muy limitado y no se integra de una manera coherente en un análisis global que permita evaluar en términos de eficiencia dinámica las diferentes instituciones y alternativas que se estudian en los

${ }^{40}$ La tesis coaseana sobre la irrelevancia de la distribución de los derechos de propiedad (con costes de transacción cero) ha sido calificada por Gary North como la «Don Corleone theory of property rights» y es radicalmente contradictoria con el enfoque de las relaciones entre la ética y la eficiencia dinámica que exponemos en este trabajo. Véase North (2002), pp. 75-100. 
capítulos correspondientes a cada libro de texto. A continuación mencionaremos los tratamientos de la eficiencia dinámica que hemos encontrado más interesantes. ${ }^{41}$

El libro de texto de Gwartney y Stroup, Economics: Private and Public Choice, ${ }^{42}$ aunque no incorpora explícitamente el término de «eficiencia dinámica», sí que explica que el mundo está en constante cambio como resultado de la creatividad empresarial y del proceso de rivalidad competitiva que desarrollan los empresarios, todo lo cual, según sus autores, obliga a que los economistas revisen las nociones tradicionales de eficiencia estática.

Mucho más explícitos en su análisis de la eficiencia dinámica son Dolan y Lindsay, ${ }^{43}$ especialmente a la hora de diferenciar entre la eficiencia estática y la eficiencia dinámica, que definen como «la capacidad de un sistema económico para trasladar hacia la derecha la curva de posibilidades máximas de producción». Por el contrario, la eficiencia estática sería «la capacidad de un sistema económico para estar o situarse sobre la curva de posibilidades máximas de producción». Además Dolan y Lindsay se refieren a las aportaciones pioneras de Schumpeter en el ámbito de la eficiencia dinámica y consideran que la innovación y los descubrimientos tecnológicos son los principales impulsores de la misma, aun cuando no dejan de mencionar la capacidad creativa de la función empresarial como aportación esencial de los teóricos procedentes de la Escuela Austriaca. Es más, los autores de este manual llegan a estimar cuáles han podido ser, desde la Segunda Guerra Mundial hasta hoy, las eventuales

${ }^{41}$ La muestra utilizada de manuales incluye libros de texto tan conocidos como los de Samuelson, Lipsey, Friedman (Milton), Fridman (David), Stiglitz, Kreps, Fisher-Dornbusch-Schmalense, Mankiw, Wonacott y Wonacott, Alchian y Allen, Sloman, Boulding, Bresciani-Turroni, Gwartney y Stroup, Dolan y Lindsay, Barre, Kasper y Streit, Hardwick-Khal-Langmead, Gimeno y Guirola, González Paz, Mochón y O'Driscoll y Rizzo.

${ }^{42}$ Gwartney y Stroup (1983), especialmente pp. 416-419.

${ }^{43}$ Dolan y Lindsay (1988), pp. 489-692. 
pérdidas de eficiencia estática que hayan podido afectar a la economía norteamericana y que cifran en una media del 2,5 por ciento del producto interior bruto norteamericano, manifestando que, en su opinión, estas pérdidas han sido más que sobradamente compensadas por las ganancias de eficiencia dinámica que se han experimentado durante ese mismo periodo como resultado de la creatividad y la fuerza coordinadora de los empresarios norteamericanos.

En 1998, Wolfgang Kasper y Manfred E. Streit publicaron un importante manual dedicado al estudio del análisis económico institucional. En este libro, sus autores definen la eficiencia dinámica como «la capacidad para adaptarse, responder y generar nuevo conocimiento». ${ }^{44}$ Como se ve, el manual de Kasper y Streit se aproxima mucho a la teoría de la eficiencia dinámica que hemos expuesto más arriba. Además, y siguiendo a Demsetz, estos autores critican el «enfoque del Nirvana» propio de la metodología neoclásica y que consiste en comparar la realidad con la utopía de la eficiencia estática. Kasper y Streit concluyen que gran parte de los denominados «fallos del mercado» no son tales desde el punto de vista dinámico, porque, o bien sirven para impulsar la creatividad y la introducción de nuevas tecnologías (tal sería el caso de los «monopolios»), o bien constituyen la más íntima característica de los mercados reales (como ocurriría en los casos de "información asimétrica», moral hazard no asegurable, inherente a todo acto empresarial, etc.). Por eso, según estos autores, el analista ha de comparar la realidad institucional no con modelos ideales irrealizables (como hasta ahora han hecho los teóricos de la economía del bienestar) sino con alternativas institucionales que sean factibles y sirvan para impulsar la creatividad y capacidad coordinadora de la empresarialidad. Vemos, por tanto, cómo Kasper y Streit completan las intuiciones de Demsetz con la teoría hayekiana sobre el surgi-

${ }^{44}$ Kasper y Streit (1998), p. 58. 
miento y creación del conocimiento que continuamente descubren los empresarios en los procesos de mercado.

O'Driscoll y Rizzo, en la misma línea, explican en su libro The Economics of Time and Ignorance, que no se debe criticar, como a menudo hacen los economistas neoclásicos, el proceso real de mercado por no estar sobre el límite de la curva de posibilidades máximas de producción, es decir, por no ser estáticamente eficiente debido a la existencia de supuestos «fallos» de mercado. $Y$ es que, según estos autores, tal crítica supone que pueda llegar a conocerse una información que sólo genera el propio proceso real de mercado y que, por tanto, si se conociera a priori haría tal proceso innecesario y redundante. Es decir, nadie puede conocer la curva de posibilidades máximas de producción porque ni siquiera está dada, sino que continuamente está trastrocándose y moviéndose hacia la derecha como resultado de la creatividad empresarial. Criticar al mercado por no encontrarse sobre un límite que nadie conoce y que continuamente está cambiando, no sólo es un grave error desde el punto de vista metodológico, sino que además puede llevar al desatino de justificar determinadas políticas de intervencionismo económico que terminen por dificultar el proceso real de mercado que, precisamente, es el principal impulsor del continuo aumento cuantitativo y cualitativo de las posibilidades de la frontera de producción. ${ }^{45}$

Finalmente, no quisiéramos terminar esta revisión de los manuales que han tratado, si bien sea someramente, el concepto de eficiencia dinámica, sin referirnos al curioso caso del libro de texto de Wonacott y Wonacott, que se empeña en definir el concepto de «eficiencia dinámica» en términos estrictamente «estáticos», es decir, como «el ritmo óptimo de los cambios». Cuál sea el ritmo de referencia que se utilice para considerar si un sistema económico se está aproximando o no al «óptimo», es algo que queda sin explicitar. Según estos autores, es el modelo de compe-

45 O’Driscoll y Rizzo (1998), especialmente pp. 88 y ss. 
tencia perfecta el que promueve la eficiencia dinámica, en la medida en que fuerza a las empresas a adoptar rápidamente nuevas tecnologías, señalando que existe un cierto debate respecto de si es la competencia o el monopolio el sistema que más impulsa la creación y descubrimiento de nuevas tecnologías. En todo caso, el tratamiento que Wonacott y Wonacott dan a la eficiencia dinámica no sólo se encuentra totalmente condicionado por su visión estática de la economía, sino que además es muy confuso (y desconcertante), pues parece como si el párrafo correspondiente se incorporase en el libro de texto para cubrir un tema que se considera de relevancia, pero sin fundamentarlo en ningún análisis dinámico sobre los procesos reales de mercado impulsados por la empresarialidad que se dan en la vida real. ${ }^{46}$

Como conclusión de este breve repaso por la literatura científica de más difusión didáctica puede afirmarse que, al margen de las aisladas excepciones ya citadas, queda aún un camino muy largo por recorrer para que los economistas acepten con carácter general y empiecen a utilizar sistemáticamente el concepto y las implicaciones de la dimensión dinámica de la eficiencia económica. Cuando esto ocurra, y en todo estudio de economía aplicada no dejen de incluirse las consideraciones sobre la eficiencia dinámica, el análisis de la concepción dinámica de la eficiencia económica terminará filtrándose a los libros de texto, y su estudio pasará a ser considerado como un contenido estándar de tratamiento imprescindible en los manuales que estudien los alumnos de economía de todo el mundo.

${ }^{46}$ Wonacott y Wonacott (1986), p. 492. 


\section{Relaciones entre la ética y la eficiencia dinámica}

\section{a) Introducción}

Ya se ha mencionado en el apartado 2.c) cómo, de acuerdo con el denominado «segundo teorema fundamental de la economía del bienestar», desarrollado en el marco estático de la teoría neoclásica, eficiencia y ética aparecen como dos dimensiones distintas que pueden combinarse de manera diferente ${ }^{47}$ En efecto, en el contexto de la economía del bienestar se considera que existen múltiples óptimos paretianos (representados por todos y cada uno de los puntos de la curva de posibilidades máximas de producción) cada uno de los cuales podría corresponder a un esquema ético de redistribución de la renta diferente. De manera que, por ejemplo, en la versión de Bergson-Samuelson, una hipotética «función de bienestar social» sería capaz de recoger el esquema redistributivo socialmente aceptable y permitiría determinar el optimum optimorum allí donde se diera el punto de intersección entre dicha función de bienestar social y la curva de posibilidades máximas de producción. Este tipo de análisis ha motivado, además, que muchos pensadores crean en la supuesta indeterminación de la teoría a la hora de evaluar un sistema económico, pues consideran que tal evaluación depende en última instancia de juicios de valor que se encuentran más allá del ámbito de la teoría económica.

Pues bien, todo este esquema, que hasta ahora se ha aceptado con carácter general, se trastroca completamente si se da entrada a la concepción dinámica de la eficiencia económica: en efecto, como vamos a ver, no todos los sistemas éticos de redistribución de la renta son compatibles con la eficiencia dinámica entendida como la creatividad y la coordinación empresarial. Se abre, así, al economista teórico, un interesantísimo campo de

${ }^{47}$ Como ya hemos visto, a una conclusión semejante puede llegarse a partir del Teorema de Coase. 
investigación que consiste, precisamente, en analizar qué principios de ética social o de justicia distributiva impulsan y son compatibles con los procesos de mercado que caracterizan la eficiencia dinámica.

\section{b) La ética como condición necesaria y suficiente de la eficiencia dinámica}

La mayor parte de los posicionamientos sobre justicia distributiva y ética social que hasta ahora se han mantenido con carácter general y que han constituido el «fundamento ético» de importantes movimientos políticos y sociales (de naturaleza «socialista» o «socialdemócrata») tiene su origen o fundamento en la concepción estática de la eficiencia económica. El paradigma de la teoría económica neoclásica hasta ahora dominante se basaba en considerar que la información es algo objetivo y se encuentra dada (bien en términos ciertos o probabilísticos), por lo que se consideraba, por un lado, que es posible efectuar análisis de costes y beneficios sobre la misma, y por otro, que, como ya se ha indicado, las consideraciones de maximización de la utilidad son totalmente independientes de los aspectos morales, por los que unos y otras pueden combinarse en diferentes proporciones.

Además, la concepción estática hasta ahora dominante llevó casi de forma inexorable a concluir que, en cierto sentido, los recursos están dados y son conocidos, por lo que el problema económico de su distribución se consideró distinto e independiente del que plantea la producción de los mismos. En efecto, si los recursos están dados, posee excepcional relevancia el analizar de cómo deberán distribuirse entre los diferentes seres humanos, tanto los medios de producción disponibles como el resultado final de los diferentes procesos productivos.

Todo este planteamiento cae por su base en la perspectiva de la nueva concepción dinámica de los procesos de mercado 
fundamentada en la teoría de la función empresarial y en el concepto de eficiencia dinámica que venimos analizando. Según esta perspectiva, todo ser humano posee una innata capacidad creativa que le permite apreciar y descubrir las oportunidades de ganancia que surgen en su entorno, actuando en consecuencia para aprovecharse de las mismas. Consiste, por tanto, la empresarialidad en la capacidad típicamente humana para crear y descubrir continuamente nuevos fines y medios. De acuerdo con esta concepción, los recursos nunca están dados, sino que tanto los fines como los medios son continuamente ideados y concebidos ex novo por los empresarios, siempre deseosos de alcanzar nuevos objetivos que ellos descubren que tienen un mayor valor. A su vez, esta capacidad creativa de la función empresarial se combina, como ya hemos visto, con la capacidad coordinadora de la misma. Y si los fines, los medios y los recursos no están «dados», sino que continuamente están creándose de la nada por parte de la acción empresarial de los seres humanos, es evidente que el problema ético fundamental deja de consistir en cómo distribuir equitativamente «lo existente», pasando a concebirse como la manera más conforme a la naturaleza humana de fomentar la coordinación y la creación empresarial.

Por tanto, en el campo de la ética social se llega a la conclusión fundamental de que la concepción del ser humano como un actor creativo y coordinador, implica aceptar con carácter axiomático el principio de que todo ser humano tiene derecho a apropiarse de los resultados de su creatividad empresarial. Es decir, que la apropiación privada de los frutos de aquello que crean y descubren los empresarios es un principio de derecho natural, porque, si el actor no pudiera apropiarse de lo que crea o descubre, entonces se bloquearía su capacidad de detectar oportunidades de ganancia y desaparecería el incentivo que tiene para llevar a cabo sus acciones. Además, el principio expuesto es universal en el sentido de que puede ser aplicado a todos los seres humanos en todas las circunstancias de tiempo y lugar concebibles. 
Este principio ético que acabamos de enunciar, y que es la base de la fundamentación ética de toda economía de mercado, posee además otras importantes ventajas características. En primer lugar, destaca la gran atracción intuitiva que el mismo tiene para todos: parece obvio que si alguien crea algo de la nada, tiene derecho a apropiarse de ello, pues no perjudica a nadie ${ }^{48}$ (antes de que creara no existía aquello que creó, por lo que su creación no perjudica a nadie y, como mínimo, beneficia al actor creativo, si es que no beneficia también a otros muchos seres humanos). En segundo lugar, el principio enunciado es un principio ético de validez universal muy relacionado con el principio tradicional del derecho romano relativo a la apropiación originaria de recursos que previamente no son de nadie (occupatio rei nullius), y que además permite resolver el paradójico problema planteado por la denominada «condición de Locke», según la cual el límite a la apropiación originaria de los recursos radica en dejar un «número suficiente» de los mismos para otros seres humanos. Y es que el principio basado en la creatividad que se acaba de enunciar hace innecesaria la «condición de Locke»: cualquier resultado de la creatividad humana no existía antes de ser descubierto o creado empresarialmente, por lo que su apropiación no puede perjudicar a nadie. La concepción de Locke, por tanto, sólo tiene sentido en un entorno estático en el que se presuponga que los recursos ya existen (están «dados»), no varían, y hay que distribuirlos entre un número predeterminado de seres humanos.

Concibiendo la economía como un proceso dinámico de tipo empresarial, el principio ético que ha de regular las interacciones sociales se basa en considerar que la sociedad más justa será aquella que de manera más enérgica promueva la creatividad empresarial de todos los seres humanos que la compongan, para lo cual es imprescindible que cada uno de ellos pueda tener la

\footnotetext{
48 Salvo en el caso de nuestro ejemplo del envidioso patológico y antisocial.
} 
seguridad a priori de que podrá apropiarse de los resultados de su creatividad empresarial y de que éstos no le serán expropiados total o parcialmente por nadie, y menos aún por las autoridades públicas.

Por otro lado, debe concluirse que el principio básico de ética social que hemos enunciado, basado en la propiedad privada de todo aquello que se crea y descubre empresarialmente y, por tanto, en el intercambio voluntario de todos los bienes y servicios, es simultáneamente la condición necesaria y suficiente de la eficiencia dinámica. Es una condición necesaria puesto que si no se respeta la propiedad privada de los frutos de cada acción humana, se bloquea el incentivo más importante para crear y descubrir oportunidades de ganancia y la fuente fundamental de creatividad y coordinación que impulsa la eficiencia dinámica del sistema (es decir, el movimiento hacia la derecha de la correspondiente curva de posibilidades máximas de producción). Pero la ética de la propiedad privada no sólo es la condición necesaria de la eficiencia dinámica, sino que es también su condición suficiente. $Y$ es que dado el impulso vital que caracteriza a todos los seres humanos, un entorno de libertad en el que no se les coaccione y que respete su propiedad privada es condición suficiente para que se desenvuelva el proceso empresarial de creatividad y coordinación que caracteriza a la eficiencia dinámica.

Bloquear en cualquier grado la acción humana libre menoscabando el derecho de propiedad de aquello que crean los seres humanos cuando actúan empresarialmente, no sólo es dinámicamente ineficiente, pues bloquea la creatividad y la capacidad coordinadora de los seres humanos, sino que además es esencialmente inmoral, pues tal coacción impide que el actor desarrolle lo que por naturaleza le es más propio, a saber, su innata capacidad para crear y concebir nuevos fines y medios actuando en consecuencia para tratar de lograr sus objetivos. En la medida en que la coacción del estado impida la acción humana de tipo empresarial, se limitará su capacidad creativa y no se descubrirá 
ni surgirá la información o conocimiento que es necesario para coordinar la sociedad. De ahí que el socialismo y, en general, el intervencionismo económico del estado no sólo sea dinámicamente ineficiente sino además éticamente reprobable. ${ }^{49}$

Precisamente son éstas las consideraciones que explican por qué el socialismo no sólo es un error intelectual, pues imposibilita que los seres humanos generen la información que el órgano director necesita para coordinar la sociedad vía mandatos coactivos, sino que, como ya hemos dicho, va contra la naturaleza del ser humano y es éticamente inadmisible. Es decir, el análisis hasta ahora realizado tiene la virtualidad de poner de manifiesto que el sistema socialista e intervencionista es inmoral, pues se basa en impedir por la fuerza que los distintos seres humanos se apropien de los resultados de su propia creatividad empresarial. De esta manera, el socialismo no sólo se manifiesta como algo teóricamente imposible y dinámicamente ineficiente, sino también y a la vez como un sistema social esencialmente inmoral, pues va en contra de la más íntima naturaleza del ser humano, al impedir que éste se realice actuando con libertad y apropiándose de los resultados de su propia creatividad empresarial. ${ }^{50}$

Según nuestro análisis, por tanto, no hay nada más (dinámicamente) eficiente que la Justicia (rectamente entendida). Es decir, desde la concepción del mercado como un proceso dinámico, la eficiencia dinámica entendida como coordinación y

49 Véase Huerta de Soto (2001) (b).

50 El ímpetu de la creatividad empresarial también se manifiesta en el ámbito de la ayuda al prójimo necesitado y de la previa búsqueda y detección sistemática de situaciones de necesidad ajena. De manera que la intervención coactiva del estado, a través de los mecanismos propios del denominado estado del bienestar, neutraliza y, en gran medida, imposibilita el ejercicio de la búsqueda empresarial de situaciones perentorias de necesidad humana y de ayuda a los prójimos (y «lejanos») que se encuentran en dificultades, ahogando así los naturales anhelos de solidaridad humana y bloqueando las acciones tendentes a ayudar a aquellos necesitados a través de la colaboración voluntaria y espontánea que tanta importancia tiene para la mayoría de los seres humanos. Este aspecto ha sido resaltado, entre otros, por Juan Pablo II en su encíclica Centesimus annus: en el centenario de la Rerum Novarum, PPC, Madrid 1991, capítulo 4, epígrafe 49, p. 92. 
creatividad surge del comportamiento de los seres humanos efectuado siguiendo unas específicas pautadas de tipo moral (en torno al respeto a la vida, la propiedad privada y cumplimiento de los contratos), de manera que el ejercicio de la acción humana sometida a estos principios éticos da lugar a un proceso social dinámicamente eficiente tal y como lo venimos definiendo en este trabajo. Y en esta óptica se hace ahora evidente por qué, desde un punto de vista dinámico, la eficiencia no es compatible con diversos esquemas de equidad o justicia (como erróneamente mantenía el segundo teorema fundamental de la economía del bienestar), sino que surge única y exclusivamente de uno de ellos (aquel que se basa en el respeto a la propiedad privada y a la función empresarial). Por eso, la oposición entre las dimensiones de eficiencia y justicia es falsa y errónea. Lo justo no puede ser ineficiente ni lo eficiente injusto. Y es que, en la perspectiva del análisis dinámico, justicia y eficiencia no son sino las dos caras de una misma moneda, lo cual, por otro lado, confirma el orden integrado y coherente que existe en el universo social. De esta manera, nuestro análisis en términos de eficiencia dinámica, no sólo nos permite descubrir qué principios éticos son los que la hacen posible, sino que además, y esto es incluso aún más importante a la vez que ambicioso, permite dar un tratamiento objetivo y científicamente unificado a todos los problemas sociales. ${ }^{51}$

\section{c) Los principios de la moral personal y la eficiencia dinámica}

Hasta ahora nos hemos referido a los principios más importantes de la ética social que constituyen el marco que hace posible la eficiencia dinámica. Fuera de este marco se encuentran los principios de la moral personal más íntima cuya influencia sobre la eficiencia dinámica hasta ahora ha sido raramente estudiada y que, en todo caso, se considera que forman parte de un ámbito

${ }^{51}$ Un análisis más detallado de las anteriores consideraciones puede leerse en Huerta de Soto (2002), pp. 193-219. 
distinto y separado del que constituyen los principios de la ética social. Sin embargo, no creemos que esta separación esté, en forma alguna, justificada. De hecho, existen una serie de principios éticos y morales de gran importancia cara a la eficiencia dinámica de los procesos sociales en relación con los cuales se da la siguiente paradójica situación: su falta de cumplimiento a nivel individual tiene un altísimo coste en términos de eficiencia dinámica, pero, por otro lado, tratar de imponerlos utilizando la fuerza coactiva de los poderes públicos, genera también graves ineficiencias desde el punto de vista dinámico. De ahí la gran trascendencia que tienen determinadas instituciones sociales a la hora de transmitir e impulsar la observancia de estos principios de moral personal que, por su propia naturaleza, no pueden imponerse por la fuerza, pero que, a su vez, son de gran importancia para hacer posible la eficiencia dinámica de la sociedad. Así, por ejemplo, a través de la religión y de la familia estos principios se internalizan por los diferentes seres humanos, que así aprenden a cumplirlos de forma habitual y a transmitirlos de generación en generación..$^{52}$ Los principios relativos a la moral sexual, a la creación y mantenimiento indefinido de la institución familiar, a la fidelidad entre los cónyuges y al cuidado de los hijos, al control de los instintos atávicos y, en concreto, a la superación y control de la envidia malsana, etc., son todos ellos de una importancia capital para que el proceso social de creatividad y coordinación se desenvuelva sin dificultades y pueda impulsar al máximo la eficiencia dinámica en la sociedad.

La inobservancia individual de los principios morales siempre, por una u otra vía, termina generando altísimos costes en términos humanos que afectan no sólo personalmente al incum-

${ }^{52}$ El papel de estas instituciones (familia, religión) cara a internalizar y convertir en habitual el cumplimiento de las normas más generales de ética social (relativas al derecho de propiedad) también es imprescindible. Toda la fuerza coactiva del estado sería insuficiente para hacer cumplir las normas más básicas de cooperación social sin la ayuda de este tipo de instituciones. 
plidor, sino también a un grupo numeroso de terceras personas, relacionadas directa o indirectamente con él, pudiendo incluso llegar a bloquear en gran medida la propia eficiencia dinámica de todo el sistema social. Mucho más grave es la generalización de los comportamientos inmorales a través de procesos sistemáticos de corrupción moral que pueden llegar a paralizar completamente el proceso social sano y eficiente. El estudio, por tanto, en la perspectiva de la teoría económica de la eficiencia dinámica, del papel que cumplen los principios de la moral personal y las diferentes instituciones sociales que hacen posible e impulsan su cumplimiento y mantenimiento, abre un vasto campo de investigación para los estudiosos que esperamos tenga una importancia determinante en el futuro.

Un ámbito que, por vía de ejemplo, puede llegar a ilustrar la posibilidad e importancia de efectuar un análisis en términos de eficiencia dinámica sobre los principios de la moral personal, puede ser el relativo al tipo de comportamiento que los cónyuges han de tratar de mantener y desarrollar, con esfuerzo y constancia, para sacar adelante sus respectivos matrimonios y hacer perdurar la institución familiar, todo ello en beneficio de sí mismos y, principalmente, de sus hijos. Y es que si, por ejemplo, por parte del padre de familia, se generalizan comportamientos en los que prepondere el deseo, más o menos frívolo, de tener siempre una acompañante joven y atractiva por encima de cualquier otra consideración, muy posiblemente terminará divorciándose de su mujer, precisamente cuando ésta haya alcanzado una edad ya madura y sus hijos sean relativamente mayores. Si se generaliza este tipo de comportamientos, muy posiblemente las mujeres empezarán a considerar, antes de decidirse a contraer matrimonio y crear una familia, el alto riesgo de verse abandonadas, justo después de haber dedicado largos años a la crianza de los hijos, y precisamente cuando su edad y capacidad se encuentra ya mermada en el mercado laboral. Como resultado de todo ello, no sólo se destruirá un mayor número de matri- 
monios y familias, sino que, además, y esto es aún más grave, disminuirá el ritmo de nuevos matrimonios y familias, se tenderá a producir un alargamiento de la soltería por parte de las mujeres con la finalidad de asegurar sus carreras profesionales y medios de vida independiente, redundando, todo ello, en una drástica disminución de la tasa de natalidad. En ausencia de movimientos migratorios que puedan paliar la disminución de la natalidad y el consiguiente envejecimiento de la población, se resentirá el proceso social de creatividad y coordinación empresarial que alimenta la eficiencia dinámica. El avance de la civilización y el desarrollo económico y social exigen un volumen siempre creciente de población que sea capaz de soportar, entre un número de seres humanos cada vez mayor, el volumen en constante aumento de conocimiento social que genera la creatividad empresarial. Y es que, en última instancia, la eficiencia dinámica depende de la creatividad y capacidad de coordinación de los seres humanos que, en igualdad de circunstancias, tenderá a aumentar conforme crezca el número de éstos, lo cual sólo se hace posible si se mantiene un marco moral determinado de normas sobre las relaciones familiares.

Es fácil entender cómo, en este contexto de las relaciones familiares, los principios de la moral personal tienen una importancia determinante cara a la eficiencia dinámica. $Y$, sin embargo, de forma simultánea, y tan sólo en apariencia paradójicamente, hay que descartar que tales principios puedan imponerse por la fuerza coactiva del estado de forma similar a como se defienden, por ejemplo, las normas jurídicas que son propias del derecho penal. En efecto, estas normas sobre todo se refieren a la prohibición de determinados comportamientos que implican el ejercicio criminal de la violencia o el engaño en contra de los seres humanos, es decir, la violencia o amenaza de violencia física, o la obtención criminal de determinados resultados mediante el engaño o el fraude. En cambio, la imposición coactiva de los principios de la moral personal daría lugar también a 
gravísimos resultados de ineficiencia dinámica: las relaciones personales de tipo familiar, por ejemplo, forman parte del ámbito de la más estrecha intimidad del ser humano, en relación con la cual es prácticamente imposible que una tercera persona pueda hacerse con toda la información que es necesaria para juzgar con conocimiento de causa ni, muchísimo menos, para poner remedio a los posibles problemas, si es que las partes implicadas no tienen el suficiente interés o deseo de solucionarlos. Elevar, en lo que a sus posibilidades de imposición por la fuerza se refiere, al mismo rango de las normas jurídicas, todo el marco de principios de la moral personal, sólo daría lugar al establecimiento de una sociedad cerrada e inquisitorial en la que prácticamente desaparecería toda la libertad individual sobre la que descansa la función empresarial que es la única capaz de inducir la eficiencia dinámica en el proceso social.

Las anteriores consideraciones evidencian la importancia de que se desarrollen procedimientos alternativos y no coactivos de control social que permitan el conocimiento, internalización y cumplimiento de las normas más íntimas de la moral personal. Entre ellos, los sentimientos y principios religiosos, a su vez también adquiridos desde la primera edad en el ámbito familiar, cumplen un papel esencial (junto con la propia presión social de los otros miembros de la comunidad y la familia). Estos principios religiosos orientan la acción de los seres humanos, los ayudan a controlar sus impulsos más atávicos y, en suma, sirven también de guía que ayuda a decidir a la hora de seleccionar aquellas personas con las cuales decidamos tener una relación más íntima e, incluso, pasar juntos el resto de nuestra vida constituyendo una familia. Personas que, en igualdad de circunstancias, habrán de ser tanto más valoradas conforme sus principios morales parezcan ser más robustos y duraderos. ${ }^{53}$

${ }^{53}$ Unas arraigadas convicciones religiosas y un comportamiento coherente con las mismas actúan como una especie de "certificado de garantía» sobre el cumpli- 
d) El surgimiento evolutivo de los principios éticos: condicionamientos institucionales de la eficiencia dinámica

En otro lugar he definido el concepto de institución como «todo esquema pautado de conducta o comportamiento»; ${ }^{54}$ en este sentido, del análisis efectuado hasta ahora es fácil deducir que el proceso social de creación y coordinación en que consiste la eficiencia dinámica, ha de ser pautado, es decir, ha de estar sometido a la ética y al derecho o, si se prefiere, a una serie de principios morales y de normas jurídicas.

En efecto, como ya se vio en su lugar, el acto empresarial básico consiste en comprar barato y vender caro, aprovechando una oportunidad de ganancia y coordinando así el comportamiento inicialmente desajustado de los agentes sociales. Este acto se frustraría o no se llevaría a cabo, si no se dieran garantías de que cada parte interviniente en el mismo fuera a cumplir sus compromisos; o si existiese, por ejemplo, algún vicio en el consentimiento de alguno de los contratantes, o si éstos lo dieran como resultado de fraudes o engaños, bien a la hora del pago, o de entregar la cosa con la calidad prometida. Por eso, principios básicos de tipo jurídico como el respeto a la vida, la posesión pacíficamente adquirida, el cumplimiento de los contratos $\mathrm{y}$, en general, de las normas jurídicas que han evolucionado consuetudinariamente y que constituyen el derecho civil y penal dan lugar al armazón o pre-requisito institucional básico que hace posible la eficiencia dinámica. Otro tanto puede decirse de los principios de la moral personal que ya se han comentado en el apartado anterior $y$, en general, del derecho natural a la propiedad privada y de sus implicaciones, que integran el

miento futuro de las obligaciones familiares, lo cual disminuye (aunque no elimina) la incertidumbre inherente en toda decisión matrimonial y la posible frustración de expectativas, impulsando, con todo ello, el ajuste y la coordinación que hacen posible una sociedad próspera dinámicamente eficiente.

${ }^{54}$ Huerta de Soto (2001), pp. 69, nota 37. 
requisito de ética social fundamental en que se basa toda la eficiencia dinámica.

El hecho de que estos principios hayan surgido de manera evolutiva no obsta para que quepa reconocer que los mismos están insertos en la naturaleza del ser humano. $\mathrm{O}$, expresado de otra forma, la naturaleza del ser humano se plasma de forma evolutiva y éste, posteriormente, y a través de su análisis racional, es capaz de depurar los principios que evolutivamente van surgiendo de sus vicios lógicos y contradicciones, reforzándolos y aplicándolos a través de una labor de exégesis a las nuevas áreas y desafíos que van surgiendo en el devenir social. Por eso, todo análisis científico de la eficiencia social en su dimensión dinámica ha de partir de reconocer que su elaboración nunca puede efectuarse en un vacío institucional o, dicho de otra manera, que el análisis teórico de la eficiencia dinámica es inseparable del estudio del marco institucional en el que se llevan a cabo los comportamientos empresariales. Por ello hay que ser especialmente críticos de la teoría económica del Nirvana hasta ahora desarrollada por los economistas neoclásicos de la economía del bienestar que, con carácter mayoritario, se empeñan en enjuiciar los procesos reales de mercado en un completo vacío institucional, es decir, de espaldas a la realidad de las interacciones humanas, tal y como las mismas se dan en el mundo que nos rodea.

Se abre así, por tanto, un inmenso campo de investigación para el teórico especializado en economía aplicada, y que consistiría en la revisión y re-evaluación de todas y cada una de las instituciones sociales (económicas, jurídicas, morales, éticas e incluso lingüísticas) analizando el papel y la capacidad de cada una de ellas cara a impulsar la eficiencia dinámica del sistema económico. En otro lugar he explicado por qué el teórico, en esta labor, ha de ser especialmente riguroso y prudente, sobre todo porque analiza realidades sociales evolutivas muy complejas que conllevan un enorme volumen de experiencia e información, conforman la naturaleza humana y muchas veces son difícil- 
mente comprensibles con el rígido instrumental conceptual del analista. ${ }^{55}$

En el siguiente y último apartado de este trabajo vamos a exponer algunos ejemplos de aplicación práctica que ilustran, si quiera sea indiciariamente, por dónde creemos que podrá evolucionar el análisis económico de las instituciones sociales en el futuro si es que se aplica de manera coherente el concepto dinámico de la eficiencia económica que hemos expuesto.

\section{Algunas aplicaciones prácticas}

A continuación vamos a mencionar algunas áreas concretas que estimamos podrían verse enriquecidas como resultado de la aplicación sistemática a las mismas del enfoque de la eficiencia dinámica que hemos propuesto en este trabajo. Como es lógico, no se trata de presentar ningún análisis, siquiera sea medianamente definitivo ni mucho menos exhaustivo, sino tan sólo de apuntar algunas ideas, en todo caso provisionales, sobre unas líneas de investigación que parecen muy prometedoras y que quedan abiertas a la futura labor de aquellos investigadores que terminen estimando que el análisis de la concepción dinámica de la eficiencia económica puede ser fructífero e interesante.

En primer lugar, debemos referirnos a la teoría impositiva. Ya hemos visto el importantísimo papel que los beneficios (y las pérdidas) empresariales (puros) tienen a la hora de orientar la acción creativa y coordinadora de los empresarios. De hecho, estos beneficios son la señal clave que orienta e impulsa el proceso de mercado que lleva hacia la eficiencia dinámica. Pues bien, si los beneficios empresariales se distorsionan por razones fiscales, puede afectarse gravemente a todo el proceso de eficiencia dinámica (es decir, a la creatividad y a la coordinación)

\footnotetext{
55 Huerta de Soto (1994), pp. 105-109.
} 
generándose así un elevado coste en términos de pérdida de eficiencia dinámica. Este coste se superpondría al denominado por la doctrina «exceso de gravamen» y que corresponde, como es bien sabido, y en la óptica del análisis económico del equilibrio, a la pérdida de eficiencia estática y que es la que hasta ahora se ha analizado con carácter exclusivo por la teoría de la imposición óptima. ${ }^{56}$

El objetivo, por tanto, consistiría en no gravar los beneficios empresariales puros con la finalidad de impulsar la eficiencia dinámica. Hay que reconocer que este objetivo de política económica presenta, en todo caso, grandes problemas prácticos, que surgen del hecho de que, en casi todas las circunstancias reales, los beneficios empresariales puros siempre aparecen indisolublemente mezclados con otras fuentes de renta (del trabajo, del capital, de la tierra, etc.). Pero estas dificultades deben servir como acicate para el analista y el investigador que, deseosos de impulsar la eficiencia dinámica, traten de encontrar nuevos procedimientos impositivos y de desarrollar reformas fiscales que minimicen su impacto negativo sobre los beneficios empresariales puros y, por tanto, sobre la creatividad y la coordinación empresarial. ${ }^{57}$

En segundo lugar, la teoría del intervencionismo (es decir, el análisis económico de la coacción institucional) también puede enriquecerse con la aplicación sistemática del enfoque dinámico.

${ }^{56}$ Según el análisis estático tradicional, se suponen constantes y conocidas las funciones de oferta y de demanda, por lo que se estima que pueden calcularse las correspondientes elasticidades que son necesarias para la aplicación operativa de la regla de Pigou: la imposición óptima sería aquella inversamente proporcional a la elasticidad de la curva de demanda de cada bien compensada por su respectiva renta.

57 También dentro del campo de la Hacienda Pública el enfoque propuesto evidencia la inexistencia en términos dinámicos de bienes públicos (en la medida en que los problemas de oferta conjunta y exclusión del consumo tienden a ser detectados y solucionados por la creatividad empresarial) por lo que desaparece la que hasta ahora se consideraba principal justificación teórica de la existencia del Estado. 
Aquí de lo que se trataría es de efectuar una revisión de todos los actos de intervención económica y regulación para, en la medida en que se plasmen en restricciones al libre ejercicio de la función empresarial, dar pie al análisis de sus posibles efectos en términos de ineficiencia dinámica. Igualmente, el diagnóstico de los problemas de ineficiencia que genera el intervencionismo económico ha de permitir idear reformas que de manera más o menos paulatina puedan llevarse a cabo con la finalidad de eliminar las trabas a la creatividad y a la coordinación actualmente existentes, impulsando así la eficiencia dinámica del sistema.

La legislación de defensa de la competencia, en tercer lugar, puede verse con una perspectiva completamente diferente si se aplica el enfoque de la eficiencia dinámica. Y es que desde el punto de vista de los procesos dinámicos del mercado impulsados por la empresarialidad, y en ausencia de trabas institucionales al libre actuar humano en cualquier ámbito empresarial, el proceso de rivalidad entre los empresarios en muchas ocasiones desemboca en que sean solamente unos pocos (e incluso uno solo) productores los que temporalmente preponderen en determinadas circunstancias específicas de tiempo y lugar que se dan en el mercado. Esto, lejos de indicar un (supuesto) «fallo del mercado», sería, por el contrario, una de las manifestaciones más típicas del éxito de dichos empresarios a la hora de satisfacer, mejor que los demás, los deseos de los consumidores (es decir, de descubrir y concebir nuevos productos, cada vez de más calidad y de colocarlos en el mercado a un precio cada vez más reducido). De manera que una legislación restrictiva en el ámbito de la «defensa» de la competencia podría tener altos costes en términos de eficiencia dinámica, en la medida en que los empresarios potenciales descuenten a priori que en caso de tener éxito (en la introducción de una determinada innovación, en el lanzamiento de un producto, o en la conquista de un mercado), los resultados de su creatividad les puedan ser intervenidos o incluso expropiados total o parcialmente por los poderes públicos. Los ejem- 
plos de Microsoft y otros son de plena actualidad y están en la mente de todos, por lo que no es necesario referirse con más detalle a los mismos. Y algo parecido a lo anterior puede decirse en relación con muchas otras prácticas como, por ejemplo, los acuerdos de precios entre oferentes, el reparto de mercados, la venta conjunta de bienes, los acuerdos sobre distribución en exclusiva, etc., que aunque puedan considerarse como medidas restrictivas desde el punto de vista de la eficiencia estática que hasta ahora ha informado, con carácter dominante, la legislación sobre «defensa» de la competencia, puede ser que tengan todo el sentido del mundo desde el punto de vista de la concepción dinámica de la eficiencia económica que protagoniza los procesos reales de mercado. ${ }^{58}$

La teoría económica del subdesarrollo, en cuarto lugar, es otro ámbito de aplicación de la teoría de la eficiencia dinámica que es muy importante. Aquí el objetivo clave de política económica consistiría en estudiar qué reformas pueden hacerse para eliminar trabas e impulsar la función empresarial de los países pobres. Y es que el empresario es, sin duda alguna, la figura protagonista en todo proceso de desarrollo económico, por lo que resulta al menos chocante, constatar cuántos miles y miles de páginas se han escrito inútilmente en el ámbito de la teoría económica del subdesarrollo, al ignorar completamente al protagonista de los procesos de crecimiento (el empresario) y ni siquiera mencionar el papel de la función empresarial en su doble faceta creativa y coordinadora. En este sentido los teóricos neoclásicos de la teoría del crecimiento y del subdesarrollo han de considerarse en gran medida responsables, por acción y omisión, de que muchas políticas económicas llevadas a cabo en los países subdesarrollados no hayan adoptado las medidas

58 Kirzner (1999), pp. 67-77. Sobre el carácter dinámicamente eficiente de las colusiones entre empresas privadas que no sean incentivadas directa o indirectamente por el estado, debe consultarse a Salin (1996), pp. 29-42. 
necesarias de protección, fomento e impulso de las clases empresariales, tanto autóctonas como las constituidas por aquellos extranjeros que deciden ejercer la función empresarial y apostar por aquellos países que son precisamente los que más lo necesitan, al encontrarse sus pobladores más próximos a un nivel de mera subsistencia económica.

En quinto lugar, el ámbito de la macroeconomía, en general, y de la teoría monetaria, en particular, también puede verse enriquecido adoptando el punto de vista de la eficiencia dinámica. Ya desde Carl Menger sabemos que el dinero surge de forma evolutiva y consuetudinaria, impulsado por la genialidad empresarial de unos pocos que descubren, antes que los demás, que consiguen mejor sus fines demandando a cambio de sus bienes y servicios un medio de intercambio fácilmente comercializable en el mercado. En la medida en que este comportamiento pautado se generaliza y se convierte en habitual surge el dinero como medio de intercambio generalmente aceptado. El dinero, por tanto, no sería necesario en un hipotético modelo de equilibrio repetitivo estática y perfectamente eficiente, puesto que en tan irreales circunstancias, al no existir un futuro incierto nadie necesitaría mantener saldo de tesorería alguno. Es, por el contrario, en la vida real plagada de incertidumbres futuras, a su vez resultado de la creatividad empresarial que constantemente crea nueva información y modifica todos los datos y circunstancias del mercado, en la que es imprescindible mantener saldos líquidos para hacer frente a un futuro continuamente cambiante e incierto. Luego el dinero, por un lado, surge de las incertidumbres que genera la creatividad empresarial y, por otro lado, hace posible que los seres humanos desarrollen su función empresarial creativa y coordinadora, al permitirles enfrentarse con el máximo de opciones abiertas al siempre incierto futuro.

Ahora bien, en esta perspectiva es importante que las instituciones monetarias no dificulten los procesos de coordinación empresarial, haciendo con ello difícil alcanzar el objetivo de 
eficiencia dinámica. Así, por ejemplo, si la creación monetaria en forma de expansión crediticia permite la financiación inicial de proyectos de inversión a un ritmo desacompasado con el del crecimiento real del ahorro voluntario de la sociedad, entonces surgirá una grave descoordinación o desajuste intertemporal entre el comportamiento de inversores y consumidores. Este desajuste se manifestará, inicialmente, en una burbuja de inversión especulativa financiada por la inflación fiduciaria que terminará afectando a los precios de los bienes de capital que tenderán a elevarse desproporcionadamente. Ese proceso de burbuja expansiva tarde o temprano terminará, no obstante, revirtiéndose en forma de una recesión económica en la que se pondrán de manifiesto los errores empresariales cometidos y la necesidad de reconvertir y reestructurar los procesos de inversión erróneamente emprendidos. ${ }^{59}$

Queda, por tanto, abierto un interesante campo de investigación consistente en la evaluación de las actuales instituciones monetarias y crediticias a la luz de la concepción de la eficiencia dinámica que hemos presentado en este trabajo y que, eventualmente, habrá de plasmarse en el diseño de una serie de reformas que, a la vez que favorezcan la creatividad empresarial, impulsen la coordinación intertemporal dificultando la aparición artificial de los desajustes que hasta ahora de forma recurrente vienen afectando a las economías de mercado desde que el sistema bancario moderno basado en la reserva fraccionaria se desarrolló a comienzos del siglo XIX.

59 A analizar estos fenómenos he dedicado todo mi trabajo Dinero, crédito bancario y ciclos económicos, Unión Editorial, 2. ${ }^{a}$ ed., Madrid 2002. Incidentalmente, el abandono de la hipótesis sobre la eficiencia estática y equilibrio de los mercados de capitales dará lugar a toda una reelaboración de la ya obsoleta teoría de los mercados financieros, que tanto daño ha hecho como fundamentación teórica de la pasada burbuja especulativa durante los años de la Nueva Economía. La nueva teoría, por contra, habrá de concebir los mercados bursátiles como un proceso dinámico de creatividad empresarial, jamás perfectamente eficiente en términos estáticos, pero tendente siempre a la eficiencia dinámica en términos de descubrimiento y creatividad de oportunidades de ganancia y coordinación empresarial. 
En sexto, y último lugar, el análisis económico del derecho, de las normas jurídicas y de las instituciones sociales que hasta ahora se ha llevado a cabo exclusivamente en base a los postulados tradicionales del análisis económico del equilibrio, necesita, quizás más que ningún otro ámbito de la economía, una completa reelaboración incorporando las nuevas intuiciones y aportaciones que sólo la concepción dinámica de la eficiencia puede proporcionar. De esta manera podrán evaluarse de forma completamente nueva las distintas normas jurídicas e instituciones sociales, en función de su capacidad para impulsar la creatividad y la coordinación empresarial. Así, el análisis económico del derecho contractual, de la responsabilidad civil, del derecho de patentes, copyrights y marcas, el análisis económico de la familia, etc., se enriquecerán muchísimo con el enfoque dinámico y en general lo mismo sucederá con cualquier otro análisis económico de las normas e instituciones que se encuentran más próximas a la realidad social que nos rodea y que, por su propia naturaleza, son siempre esencialmente dinámicas.

Como es lógico, los anteriores ejemplos e ilustraciones no agotan, ni muchísimo menos, las posibilidades de aplicación práctica de la concepción dinámica de la eficiencia económica que, como hemos indicado, puede y debe utilizarse en cualesquiera de los ámbitos de la economía tanto teórica como aplicada. Nuestra máxima esperanza es que las ilustraciones anteriores sirvan como acicate a los jóvenes estudiosos e investigadores de nuestra disciplina y que, como consecuencia de su esfuerzo, sus aportaciones se vean enriquecidas y coronadas con el éxito. 


\section{Conclusiones}

Las principales conclusiones del presente trabajo son las siguientes:

1. a La eficiencia dinámica puede considerarse como la capacidad de un sistema económico para impulsar la creatividad y la coordinación empresarial.

2. ${ }^{a}$ La eficiencia dinámica es, sin embargo, una dimensión que hasta ahora ha sido prácticamente ignorada por la mayoría de los economistas profesionales que, con carácter exclusivo, se han centrado en la dimensión meramente asignativa o estática de la eficiencia económica.

3. ${ }^{a}$ Sin embargo, la eficiencia dinámica puede considerarse que es la dimensión más relevante del concepto económico de eficiencia, especialmente en un mundo real que nunca puede lograr el equilibrio y en el que el ideal de eficiencia asignativa o estática es por definición inalcanzable.

$4 .^{a}$ Aunque ambas dimensiones de la eficiencia (la estática y la dinámica) no son necesariamente excluyentes, sino que en muchos casos son complementarias, existen sin embargo diversos comportamientos e instituciones que, aunque aparentan ser asignativa o estáticamente ineficientes, sin embargo son capaces de impulsar de manera muy enérgica la eficiencia dinámica. Se abre así un interesante campo al estudioso y al investigador consistente en analizar los posibles trade-off entre ambas dimensiones de la eficiencia y en diseñar propuestas de reforma que tiendan a impulsar la creatividad y la coordinación empresarial.

5. ' La eficiencia dinámica, lejos de ser compatible con distintos esquemas de comportamientos éticos, surge de uno solo de ellos: de aquel que más respeta la propiedad privada y en concreto la apropiación de los resultados de la creatividad empresarial. De esta manera el concepto dinámico de eficiencia y la ética aparecen como dos caras de la misma moneda. Además, y con carácter novedoso, se ha argumentado que los principios básicos de la moral personal que han preponderado a lo largo 
de la evolución humana tienden igualmente a impulsar la eficiencia dinámica. Nuestra concepción dinámica del análisis económico puede permitir, por tanto, un tratamiento científico unificado de los diferentes problemas sociales, en los cuales las dimensiones relacionadas con la eficiencia y la justicia, lejos de considerarse mundos ajenos o separados, se autoexplican y refuerzan mutuamente.

6. ${ }^{a}$ Por todo lo anterior, estimamos que ningún análisis de eficiencia económica debería olvidar la dimensión dinámica. Es decir, en todos los estudios de economía aplicada, el analista debe introducir la pregunta de cuáles son los efectos en términos de eficiencia dinámica de la norma o institución analizada o de las propuestas de reforma que se estén estudiando. De esta manera la eficiencia dinámica se convertirá en un elemento básico a considerar siempre en todo estudio de economía, lo cual no sólo abre un inmenso y esperamos que muy fructífero campo a los futuros investigadores de nuestra disciplina, sino que, además, estamos seguros de que habrá de redundar en un desarrollo de la ciencia económica al servicio de la humanidad mucho más fructífero y dinámicamente eficiente. 


\section{REFERENCIAS BIBLIOGRÁFICAS}

Alchian, A. y Allen, W.R. (1964). University Economics, California, Wadsworth Publishing Co., Belmont.

BlánqueZ, A. (1988). Diccionario Latino-Español, Español-Latino. Barcelona, Edit. Ramón Sopena, Tomo I.

BLAUG, M. (1998). «The disease of formalism in Economics, or bad games that economists play», Jena, Lectiones Jenenses.

BuCHANAN, J.M. (1979). What Should Economists Do?, Indianápolis, Liberty Fund.

CoRDATO, R.E. (1992). Welfare Economics in an Open Ended World: A Modern Austrian Perspective, Dordrecht, Holanda, Kluwer Academic Publishers.

Demsetz, H. (1989). Efficiency, Competition and Policy, Londres, Basil Blackwell.

DolAN, E.G. y LiNDSAY, D.E. (1988). Economics, Nueva York, quinta edición, Dryden Press.

FrANTZ, R. (1988). X-Efficiency: Theory, Evidence and Applications, Boston y Dordrecht, Kluwer Academic Publishers.

GÁmIR, L. (1996). La economía del bienestar, Madrid, Fundación Argentaria, Grandes Cuestiones de la Economía, número 8.

Gwartney, J.D. y Stroup, R. (1983). Economics: Private and Public Choice, Nueva York y Londres, tercera edición, Academic Press. HuerTA DE SOTO, J. (2001) (a). La Escuela Austriaca: mercado y creatividad empresarial. Madrid, Editorial Síntesis.

HuerTA DE SOTO, J. (2001) (b). Socialismo, cálculo económico y función empresarial, Madrid, Unión Editorial, segunda edición (primera edición de 1992).

HuerTA DE SOTO, J. (2002) (a). Dinero, crédito bancario y ciclos económicos. Madrid, Unión Editorial, $2^{\text {a }}$ edición.

HUERTA DE SOTO, J. (2002). (b). «Socialismo, corrupción ética y economía de mercado», capítulo 8 de Nuevos estudios de economía política, Madrid, Unión Editorial, pp. 193-219.

HuERTA DE SOTO, J. (1994). «Historia, ciencia económica y ética social», Estudios de economía política, Madrid, Unión Editorial, pp. 105-109. 
JeNOFONTE (1966). Económico, Madrid. Edición, traducción y notas por Juan Gil, Sociedad de Estudios y Publicaciones.

KASPER W. y STREIT, M.E. (1998). Institutional Economics, Aldershot, Inglaterra, Edward Elgar.

KEYNES, J. (1973). Collected Writings, Londres, Macmillan, vol. VII y vol. XXVIII.

KIRZNER, I. (1997). How Markets Work: Disequilibrium, Entrepreneurship and Discovery, Londres, Institute of Economic affairs (IEA), Hobart Paper n. ${ }^{\circ} 133$.

KIRZNER, I. (1998). «Austrian Economics, The Coordination Criterion and Classical Liberalism», Journal des Économistes et des Études Humaines, vol. 8, n. ${ }^{\circ}$ 2/3, Junio-Septiembre 1998, pp. 187-200.

KIRZNer, I. (1979). Perception, Opportunity and Profit, Chicago, The University of Chicago Press.

KIRZNER, I. (1973). Competition and Entrepreneurship, Chicago, University of Chicago Press (2. ${ }^{\text {a }}$ edición española, Madrid 1998, Unión Editorial).

KIRZNER, I. (diciembre 1998-enero 1999). «Los objetivos de la política antitrust: una crítica», Información Comercial Española, n. ${ }^{\circ}$ 775, pp. 67-77.

LeIBENSTEIN, H. (1966). «Allocative Efficiency vs. X-Efficiency», American Economic Review, n. ${ }^{\circ}$ 56, pp. 392 a 415.

LIPSEY, R.G. (1973). Introducción a la Economía Positiva, Barcelona, Edit. Vicens-Vives.

MAYER, H. (1994). «The cognitive value of functional theories of price: critical and positive investigations concerning the price problem», cap. 16 de Classics in Austrian Economics: A sampling in the history of a tradition. Londres, I.M. Kirzner (ed.), vol. II, William Pickering.

MiROWSKI, P. (1989). More Heat than Light: Economics as Social Physics, Physics as Nature's Economics. Cambridge, Cambridge University Press.

MirowsKI, P. (2002). Machine Dreams. Cambridge, Cambridge University Press.

NoRTH, D.C. (1990). Institutions, Institutional Change and Economic Performance, Cambridge y NY, Cambridge University Press. 
NORTH, D.C. (1999). Understanding the Process of Economic Change, Londres, Institute of Economic Affairs (IEA).

NORTH, G. (otoño 2002). «Undermining Property Rights: Coase and Becker», Journal of Libertarian Studies, vol. 16, n. ${ }^{\circ} 4$, pp. 75100.

O'DrisCOLL, G.P. y RIzzO, M.J. (1998). The Economics of Time and Ignorance, Londres, Routledge.

RAICO, R. (1997). «Keynes and the Reds», The Free Market, n. ${ }^{\circ}$ de Abril.

RobBiNS, L. (1972). An Essay on the Nature and Significance of Economic Science, Londres, Macmillan y St. Martin's Press.

RothbARD, M. (1999). Historia del pensamiento económico, volumen I, El pensamiento económico hasta Adam Smith. Madrid, Unión Editorial.

Rothbard, M. (1979). «Comment: The Myth of Efficiency», en Mario J. Rizzo (ed.), Time, Uncertainty and Disequilibrium, Massachusetts, Lexington Books, p. 95.

ROTHBARD, M. (1997). «Toward a Reconstruction of Utility and Welfare Economics», en The Logic of Action One: Method, Money and the Austrian School, Cheltenham, Inglaterra, Edward Elgar, pp. 211-254.

SAliN, P. (1996). "Cartels as Efficient Productive Structures», The Review of Austrian Economics, vol. IX, número 2, pp. 29-42.

SCHUMPETER, J.A. (1944). Teoría del desenvolvimiento económico, traducción española de Jesús Prados Arrarte, Méjico, Fondo de Cultura Económica.

SCHUMPETER, J.A. (1971). Capitalismo, socialismo y democracia, Madrid, Editorial Aguilar.

STIGLER, G.J (1976). «The Existence of X-Efficiency», American Economic Review, n. ${ }^{\circ}$ 66, pp. 213-216.

STRINGHAM, E. (verano de 2001). "Kaldor-Hicks Efficiency and the Problem of Central Planning», The Quarterly Journal of Austrian Economics, vol. IV, número 2, pp. 41-50.

StromberG, J.R. (otoño 2002). «Douglas C. North and Non-Marxist Institutional Determinism», Journal of Libertarian Studies, vol. 16, n. ${ }^{\circ} 4$, pp. 101-137. 
TAYLOR, F.W. (1967). The Principles of Scientific Management, Nueva York y Londres, W.W. Norton and Company (primera edición de 1911).

WALras, L. (1909). «Economique et Mécanique», Bulletin de la Société Vaudoise de Sciences Naturelles, n. ${ }^{\circ} 45$.

WONACOTT P. y WONACOTT, R. (1986). Economics, Nueva York, Mc Graw-Hill.

ZERBE, R.O. (2001) Economic Efficiency in Law and Economics, Cheltenham, Inglaterra, Edward Elgar. 